\title{
Nécropoles et sanctuaires du plateau d'Ilouraton
}

\section{Vladimir Andreevič Khršanovskij}

Traducteur : Laurent Auberson

\section{(2) OpenEdition}

Journals

Édition électronique

URL : https://journals.openedition.org/edl/1779

DOI : $10.4000 /$ edl. 1779

ISSN : 2296-5084

Éditeur

Université de Lausanne

Édition imprimée

Date de publication : 15 mai 2019

Pagination : 411-458

ISBN : 978-2-940331-70-3

ISSN : 0014-2026

\section{Référence électronique}

Vladimir Andreevič Khršanovskij, « Nécropoles et sanctuaires du plateau d'llouraton », Études de lettres [En ligne], 309 | 2019, mis en ligne le 15 mai 2021, consulté le 17 mai 2021. URL : http:// journals.openedition.org/edl/1779; DOI : https://doi.org/10.4000/edl.1779 


\section{NÉCROPOLES ET SANCTUAIRES DU PLATEAU D'ILOURATON}

Cette contribution dresse le bilan des recherches archéologiques effectuées sur le plateau d'Ilouraton, du nom de la petite ville fortifiée qui, aux confins occidentaux du royaume du Bosphore, exista du milieu du ${ }^{\text {er }}$ s. apr. J.-C. aux années 260. Les fouilles effectuées durant de nombreuses années (1947-2013) au sud du site fortifié ont permis la découverte de plus de deux cents monuments funéraires commémoratifs et sanctuaires. Ils se répartissent en trois nécropoles contemporaines: la première à inhumations en pleine terre, la seconde à tombeaux creusés dans la roche et la troisième de type mixte. La diversité des types d'aménagements funéraires et commémoratifs, ainsi que leur répartition spatiale ne permettent pas de répondre à la question de leur rapport avec la population d'Ilouraton. De nombreux indices d'utilisation secondaire et l'apparition de nouveaux aménagements postérieurs à l'abandon d'Ilouraton (datant du IV ${ }^{\mathrm{e}}$ au XIII siècle) interdisent de les mettre en relation exclusivement avec la ville fortifiée antique d'Ilouraton et donnent des raisons de supposer qu'aux yeux des hommes de l'Antiquité, ce plateau avait en soi un statut «sacré» et mérite donc d'être considéré comme un site archéologique à part.

\section{Situation géographique du plateau d'Ilouraton}

Le milieu de la péninsule de Kertch - depuis la dépression et le lac de Čurbaš au nord jusqu'au lac salé de Tobečik au sud - est occupé par un ensemble de collines assez étendu (environ $10 \mathrm{~km}$ de largeur) qui ne porte pas de nom et comprend plusieurs chaînes de hauteurs culminant de 50 à $120 \mathrm{~m}$ au-dessus du niveau de la mer (selon le système altimétrique de la Baltique). À partir de la baie de Kertch, cet ensemble s'étire vers l'ouest et s'abaisse 10 à $15 \mathrm{~km}$ plus loin, tantôt s'interrompant brusquement vers des lacs salés ou des lits de rivières à sec, tantôt 
descendant en pente douce vers la plaine steppique, avec des chaînes de calcaire bien individualisées, assez élevées.

La dépression de Čurbaš, qui marque la frontière nord de cette élévation de terrain, est, à en juger d'après la topographie générale, l'ancien lit d'une rivière à débit important (réduit maintenant à un petit ruisseau torrentiel qui se dessèche périodiquement, avec des retenues artificielles et des digues), rivière qui coulait de l'ouest vers l'est et se jetait dans la baie de Kertch. Contournant l'extrémité nord-ouest d'une hauteur de terrain - un petit plateau d'une altitude atteignant $70 \mathrm{~m}$ et s'étendant du sud au nord (1 km x 300-400 m) - la rivière formait un méandre vers le nord, avant de s'orienter vers l'est.

Sur la rive gauche, en pente douce et submersible, se trouve maintenant le village d'Ivanovka. La rive droite, escarpée, a transformé les versants ouest et nord du plateau calcaire en un site bien fortifié (fig. 1). À l'est et au sud-est, une dépression qui s'étend sur environ $1 \mathrm{~km}$ forme sa limite naturelle. Sa partie supérieure passe entre deux ensembles de collines dans la partie sud et sud-ouest du plateau. Vers le nord/nordest, elle descend et s'élargit continuellement jusqu'à l'intersection avec le lit de l'ancienne rivière (l'actuelle dépression de Čurbaš) (fig. 2). La dénivellation est d'environ $30 \mathrm{~m}$.

Un site aussi favorable et relativement sûr ne pouvait manquer d'attirer l'attention. Selon une hypothèse formulée sur la base du matériau à disposition dans les années 1950 , l'endroit aurait déjà été habité à l'époque hellénistique ${ }^{1}$. Les recherches effectuées sur le plateau d'Ilouraton au cours des dernières décennies ont fourni des éléments qui viennent indirectement à l'appui de cette thèse ${ }^{2}$. Et c'est à cet endroit - à la frontière occidentale du royaume du Bosphore - que fut fondée, dans les années 30-50 apr. J.-C., une ville fortifiée que Viktor Francevič Gajdukevič identifiait à la cité d'Ilouraton mentionnée par Ptolémée (III.6.5) ${ }^{3}$, ce qui est confirmé par les recherches plus récentes ${ }^{4}$.

I. V. F. Gajdukevič, «Ilurat», p. 17.

2. V. A. Khršanovskij, «Arkheologičeskie issledovanija Iluratskogo plato (retrospektiva i perspektiva)", p. 180 sq.

3. V. F. Gajdukevič, «Bosporskij gorod Ilurat», p. 203 sq. et «Ilurat», p. 14.

4. V. G. Zubarev, Severnoe Pričernomor'e v istoriko-geografičeskoj koncepcii Klavdija Ptolemeja, p. 63-67. 


\section{Histoire des recherches sur le plateau d'Ilouraton}

Le découvreur d'Ilouraton, Paul Du Brux, qui, sur ses plans du territoire limitrophe au sud, datés des années 1827-1828, en faisait une acropole ou une forteresse («le palais des tsars du Bosphore»), avait observé à une verste de la citadelle un "champ des morts" avec des "grottes", soit une nécropole à hypogées creusés dans la roche, mais sans mettre ces deux sites en relation l'un avec l'autre 5 .

Dans le bilan des explorations de la fin des années 1930 et des années 1940, Gajdukevič mentionne une seconde nécropole (de tombes en pleine terre) sur le territoire du village d'Ivanovka (appelée «nécropole du bas»), qui à son avis était précisément liée à la citadelle d'Ilouraton ${ }^{6}$.

En 1947, exactement cent vingt ans après Du Brux, une des équipes de la mission archéologique du Bosphore Cimmérien, composée d'étudiants de l'Institut pédagogique Herzen de Leningrad, sous la direction de Mikhail Moisevič Kublanov, commença des recherches dans les vestiges de la ville et dans le territoire voisin au sud. Dans le secteur nord de ce territoire, à $300 \mathrm{~m}$ à l'est de la tour fortifiée sud d'Ilouraton, fut découvert un caveau à voûte en berceau, fait de moellons de calcaire posés à sec, qui reçut le numéro 1, et, en rapport avec le caveau, un nouveau secteur nord de la nécropole d'Ilouraton. Dans la partie sud du plateau, des fouilles furent effectuées dans l'une des "grottes" de la nécropole de Du Brux, l'hypogée $n^{0} 5$, comprenant une chambre en forme de caverne ménagée dans la roche et, menant vers elle depuis l'ouest, un dromos à ciel ouvert dans lequel se trouvait la sépulture d'un cheval ${ }^{7}$.

À la différence de Gajdukevič, qui ne rattachait pas les hypogées creusés dans la roche au site d'Ilouraton ${ }^{8}$, Kublanov, après ses recherches de 1968 à 1979, était d'avis que tous les complexes funéraires et commémoratifs sur le haut du plateau (la "nécropole du haut») appartenaient aux habitants d'Ilouraton, même s'ils peuvent se rapporter à différentes traditions ethnoculturelles 9 . Quant à la "nécropole du bas ", à sépultures

5. P. Du Brux, Sobranie sočinenij, t. I, p. 80 sq., 310 ; t. II, fig. 510.

6. V. F. Gajdukevič, «Bosporskij gorod Ilurat», p. 189 et «Ilurat», p. 138 sq.

7. M. M. Kublanov, «Itogi arkheologičeskikh izyskanij v rajone der. Ivanovka (Kerčenskij poluostrov) v 1947 godu»; V. F. Gajdukevič, "Bosporskij gorod Ilurat», p. 203 sq. et «Ilurat», p. 138.

8. Ibid., p. 139 sq.

9. M. M. Kublanov, «Raskopki nekropolja Ilurata», p. 101, 125-128. 
Fig. 3 - Plateau d'Ilouraton. Plan de situation des nécropoles et des sanctuaires. Plan topographique (dressé en 2006) de Jurij Kutimov. Infographie de D. Glauser (c) UNIL/IASA. 
en pleine terre, sur laquelle se trouve pratiquement le village d'Ivanovka (et dont la superficie, selon des données provisoires, était d'au moins 5 ha), elle pouvait, à son avis, se rapporter à «des lieux habités non encore découverts" ${ }^{10}$.

De 1984 à 2013, au cours de trente campagnes de fouilles, l'expédition archéologique du Musée national d'histoire de la religion (jusqu'en 2008), puis de l'Institut d'histoire de la culture matérielle de l'Académie des sciences de Russie (de 2009 à 2013), sous la direction de l'auteur de ces lignes, effectua des recherches sur le plateau d'Ilouraton. Au terme de cette exploration, il est établi qu'à une distance de 400 à $700 \mathrm{~m}$ à l'est, au sud et au sud-ouest de la tour d'angle sud de la forteresse d'Ilouraton, en plus des secteurs connus auparavant, on peut distinguer trois zones funéraires (sud, nord et sud-ouest, fig. 3) qui forment des nécropoles distinctes appartenant peut-être à des groupes ethnoculturels différents.

\section{La nécropole sud à sépultures taillées dans la roche}

La zone funéraire sud, située à $700 \mathrm{~m}$ au sud d'Ilouraton sur une hauteur rocheuse, fut découverte en 1827 par Paul Du Brux et indiquée sur son plan en plus des vestiges de la ville. Selon quelques témoins, Du Brux réalisa même les premières fouilles de cette nécropole "à hypogées" ${ }^{11}$. Gajdukevič cite le témoignage de Du Brux, selon lequel «il ne se trouve au fond de ces tombeaux que des squelettes humains et de la simple poterie d'argile de facture grossière» ${ }^{12}$. En 1947, une équipe dirigée par Kublanov et intégrée à la mission archéologique de Gajdukevič dans le Bosphore Cimmérien, commença les investigations sur le site de la ville d'Ilouraton et des nécropoles du plateau. Les fouilles systématiques du plateau ne furent toutefois reprises qu'en 1968 par Kublanov, à la tête cette fois-ci de la mission archéologique du Musée national d'histoire de la religion.

De la fin des années 1960 aux années 1970, les travaux portèrent essentiellement sur cette même nécropole sud à sépultures taillées dans

\footnotetext{
IO. Ibid., p. 101, n. 10 .

II. I. V. Tunkina, Russkaja nauka o klassičeskikh drevnostjakh juga Rossii (XVIIIseredina $X I X v v$.), p. 153.

I2. V. F. Gajdukevič, «Bosporskij gorod Ilurat», p. 189.
} 
la roche. Cinq campagnes (1968, 1969, 1970, 1972 et 1979) amenèrent à la mise au jour et à l'étude d'une quarantaine de structures funéraires et commémoratives.

Outre quatorze hypogées à dromos à découvert taillé dans la roche et chambre funéraire en forme de grotte (d'un type semblable à celles qu'avaient vues Du Brux et Gajdukevič), on mit au jour six caveaux creusés à couverture maçonnée (l'un - le n ${ }^{\circ} 11$ - en berceau), deux caveaux construits en maçonnerie de moellons de calcaire équarris et posés à sec (un avec une voûte en berceau et l'autre avec une voûte en encorbellement), neuf tombes taillées dans la roche, deux tombes à dalles, des vestiges de repas funéraires et des restes de taille de la pierre.

Parmi ces hypogées, les $\mathrm{n}^{\text {os }} 19$ et 37 se signalent par leurs dimensions et leurs particularités de construction, et les $n^{\text {os }} 18$ et 32 par leur construction en moellons de calcaire posés à sec.

Le premier hypogée ( $\left.n^{\circ} 19\right)$ comprenait un dromos d'une longueur d'environ $5,5 \mathrm{~m}$, menant depuis le nord-ouest vers une chambre funéraire d'une surface de $21 \mathrm{~m}^{2}$ et d'une hauteur au plafond (taillé par en-dessous dans la masse rocheuse) de 2,5 m. Le sol était pavé de grandes dalles de calcaire, trois parois revêtues de gros moellons de calcaire et la quatrième stuquée ${ }^{13}$.

L'hypogée $\mathrm{n}^{\circ} 37$ comprenait deux chambres (fig. 4). Dans le dromos $(2,2 \times 1,2 \mathrm{~m})$, tourné vers l'ouest avec une légère déviation vers le sud, et dans la première chambre (funéraire) $(3,36 \times 2,3 \mathrm{~m})$, les murs étaient construits en moellons de calcaire. L'assise inférieure dans la chambre funéraire était stuquée et décorée de couleur ocreuse. La chambre funéraire était séparée du dromos par une épaisse dalle de fermeture encore in situ $(1,5 \times 1,3 \times 0,3 \mathrm{~m})$. La seconde chambre funéraire se présentait sous la forme d'une cavité creusée à même la roche $(2,35 \times 2,25 \mathrm{~m})$.

Derrière l'assise inférieure conservée de la maçonnerie du mur côté est, qui séparait les deux chambres, face à une baie d'entrée supposée, était creusée dans le sol rocheux une fosse en forme d'entonnoir de $50 \mathrm{~cm}$ de profondeur. Au-dessus de la fosse reposait la moitié inférieure du squelette d'un homme adulte de constitution robuste, entourée d'un demi-cercle de petites pierres en disposition peu serrée. Dans la terre furent découverts des petits charbons épars. L'emplacement du squelette

I3. M. M. Kublanov, «Novye pamjatniki nekropolja Ilurata» et "Raskopki nekropolja Ilurata», p. 104. 
Fig. 4 - Nécropole sud à tombeaux creusés dans la roche. Hypogée nº 37. Vue depuis l'ouest. Photographie de Larisa Assel'.

et les vestiges d'un rituel accompli permettent de supposer qu'il s'agit d'un sacrifice humain. À côté du squelette de l'homme furent retrouvés encore des ossements de cheval, d'un mouton, d'un renard, d'un lièvre et d'oiseaux, animaux peut-être aussi apportés en offrande.

À en juger par le mobilier archéologique, peu abondant, mis au jour (fragments d'une amphore en argile claire à col étroit, d'assiettes à vernis rouge, de pots "de cuisine», de cruches en argile grise, tessons de flacons à parfum et d'autres vases de verre, partie supérieure d'une terre cuite, perles), la période d'utilisation de cette construction funéraire se situe au II ${ }^{\mathrm{e}}$-III ${ }^{\mathrm{e}}$ s. apr. J.-C. ${ }^{14}$.

I4. M. M. Kublanov, V. A. Khršanovskij, «Nekropol’ Ilurata», p. 31-35. 
Le caveau à double chambre funéraire $\mathrm{n}^{\mathrm{o}} 18$, à voûte en berceau, n'était pas d'aussi grandes dimensions, mais se distinguait par la complexité des formes architecturales. Les deux chambres, de 7,5 et $4 \mathrm{~m}^{2}$ respectivement, se situaient à des niveaux différents (la seconde 1,2 $\mathrm{m}$ plus haut que la première), et étaient couvertes de deux voûtes liées l'une à l'autre, mais autonomes et de portées différentes ${ }^{15}$.

Le caveau $n^{\circ} 32$ comprenait une chambre funéraire assez spacieuse, d'une surface d'environ $17 \mathrm{~m}^{2}$. Sa voûte en constituait certainement l'élément architectural le plus remarquable. Les pierres d'angle conservées sont des pendentifs qui témoignent indiscutablement d'une voûte en encorbellement.

Les éléments de base du rite funéraire et la datation des objets découverts (orientation avec l'entrée vers l'ouest, vestiges de feux allumés dans la chambre funéraire et grand dépôt de cendres laissé par un bûcher rituel à l'extérieur, à côté du dromos, objets funéraires découverts durant la fouille: vaisselle à vernis rouge, lampe à vernis rouge avec une figure de Néréide chevauchant un dauphin, statuette de terre cuite de Cybèle, perles, fragments d'objets de bronze) s'inscrivent dans l'image d'ensemble que donne la nécropole. Toutefois, six croix gravées sur les murs de la partie orientale du caveau sont totalement inattendues et sortent des cadres chronologiques et rituels connus.

Ces croix ont été gravées avant l'effondrement de la voûte du caveau. Kublanov date le mobilier funéraire le plus récent, provenant de la chambre du caveau, du milieu du IV ${ }^{\mathrm{e}}$ s. apr. J.-C., mais situe son utilisation en lien avec une symbolique chrétienne à une période encore plus tardive, aux $\mathrm{V}^{\mathrm{e}}-\mathrm{VI}^{\mathrm{e}}$ siècles ${ }^{16}$.

Contrairement à Du Brux, Kublanov était d'avis que ce cimetière creusé dans le rocher avait été, dans l'Antiquité, une nécropole de kourganes. Selon ses observations, les voûtes maçonnées des caveaux funéraires s'élevaient un peu au-dessus de la surface du terrain et, ne serait-ce que pour cette raison, ne pouvaient pas ne pas avoir été couvertes d'un remblai. Dans beaucoup de cas, les vestiges de remblais de

I5. M. M. Kublanov, "Raskopki nekropolja Ilurata v 1969 g.", p. 86-88; M. M. Kublanov, S. D. Kryžickij, «Sklep no 18 nekropolja Ilurata».

I6. M. M. Kublanov, «Novye pogrebal'nye sooruženija Ilurata» et «Raskopki nekropolja Ilurata», p. 110-112, 120-122. 
kourganes et de tertres à pierres dressées ont en effet pu être constatés archéologiquement.

Les rites funéraires révélés par les premières campagnes de fouilles sur la nécropole méridionale du plateau d'Ilouraton présentent certains traits caractéristiques. Du Ir au III siècle, seule l'inhumation des corps fut pratiquée. Dans les rares cas où il a été possible de l'établir, le défunt était étendu sur le dos, la tête tournée vers l'est et les pieds vers l'ouest. Dans la majorité des caveaux, un corridor - le dromos - menait à la chambre funéraire; il était également tourné vers le soleil couchant.

Aucun squelette intact de corps inhumés pendant l'Antiquité n'a été découvert dans les caveaux et les hypogées. Les restes osseux de quelques-uns d'entre eux permettent cependant de conclure qu'il ne s'agissait pas de sépultures individuelles, mais de tombeaux de famille (ou ayant eu en dernier lieu cette fonction, différente alors de la première). Quelques crânes provenant du caveau creusé $n^{\circ} 24$ présentaient une importante caractéristique anthropologique: des traces manifestes d'une déformation de la région sincipitale-frontale par un bandeau de serrage, pratiquée du vivant de l'individu ${ }^{17}$.

Les vestiges, en assez grand nombre, de rites commémoratifs (repas funéraires) peuvent également être rangés au nombre des caractéristiques de cette nécropole. Parmi ces rites, certains se distinguaient par une répartition spatiale particulière dans les intervalles entre les tombes, sur des "places rituelles» consistant en dépôts de cendres (restes de bûchers) remplis d'une grande quantité de débris de vaisselle à vernis rouge et de céramique modelée, d'amphores, de pots de cuisine, de verre fondu, de fragments de statuettes de terre cuite, de lampes et d'objets métalliques d'usage courant (tête de clou, boucle, charnière de couvercle de coffret). Les objets découverts dans les dépôts de cendres avaient visiblement été intentionnellement cassés, ou utilisés dès le début à l'état fragmentaire. Ce n'est pas par hasard non plus qu'ils avaient tous été jetés dans le bûcher. À en juger par les objets découverts lors des premières campagnes de fouilles, le feu jouait un très grand rôle dans le rituel funéraire des habitants du plateau d'Ilouraton. On a retrouvé de nombreux charbons dans la terre du remblai des tombes, et des traces de combustion (taches de cendres, suie, pierres brûlées) dans les dromos et sur le sol des chambres funéraires.

I7. Ibid., p. 127. 
Sous le dépôt de cendres d'une «aire rituelle» ont en outre été mises au jour des sépultures de chiens, et, non loin de là, le squelette entier d'un cheval, avec le crâne déposé à part. Une sépulture de cheval avait déjà été découverte lors des premières fouilles de la nécropole en 1947, dans le dromos de l'hypogée $\mathrm{n}^{\circ} 5$. Ces sépultures de chevaux n'ont révélé aucune trace de pièces de harnachement.

Le mobilier funéraire de la nécropole taillée dans le rocher présente un faciès assez diversifié et en même temps typique des nécropoles bosporanes de cette époque qui sont éloignées de la mer. Seuls des fragments d'amphores épars ont été trouvés dans les tombes. Parmi la vaisselle de table, les céramiques "d'apparat" à vernis rouge (assiettes, tasses, petites cruches, coupes) étaient prédominantes. La poterie en argile rouge et la céramique modelée étaient plus rares. Parmi les découvertes isolées, il faut mentionner des lampes (à vernis rouge et en argile grise) et des flacons à parfum en verre.

Pour ce qui concerne les objets de parure provenant des tombes et des caveaux, on recense principalement des anneaux de bronze, des bagues, des bracelets, des boucles d'oreille et des perles (faïence égyptienne, calcédoine, agate, cornaline). Les objets de la vie courante sont des agrafes de bronze, des fibules, des boucles, des aiguilles, ainsi que des petits couteaux en fer et des pierres à aiguiser. On a également recueilli des armes: poignards courts en fer, épées longues et étroites, pointes de flèches et restes en cuir d'un étui à arc et flèches. La quantité considérable de clous en fer amène à supposer que les inhumations se faisaient dans des cercueils de bois ${ }^{18}$.

Les "miroirs sarmates" découverts dans des tombes soulignent la touche «barbare» particulière de la nécropole: il s'agit de petits médaillons métalliques percés de deux trous de suspension sur les côtés, avec une face lisse polie et l'autre ornée de représentations en relief (disque solaire à lignes formant les rayons et, parfois, en plus, des "pattes d'oiseau»). Lorsque cela a pu être établi, ces miroirs avaient été brisés intentionnellement et les fragments déposés ensemble, la face décorée vers le haut ${ }^{19}$.

Lors des recherches complémentaires effectuées dans les caveaux funéraires pillés et détruits à une époque ancienne déjà, on a découvert

I8. Ibid., p. 112-120.

I9. Ibid., p. 115. 


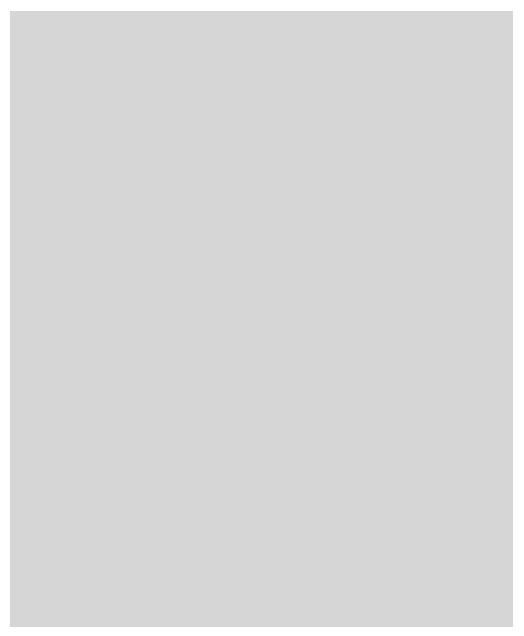

Fig. 5 - Nécropole sud à tombeaux creusés dans la roche. Anneau gravé découvert dans le caveau $\mathrm{n}^{\circ} 25$ et portant les

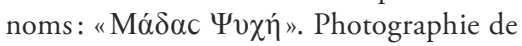
Vladimir Koren'kov. plusieurs objets en or: grains de collier cannelés, perle de collier, pendentif incrusté de pâte verte, boucle d'oreille, anneau. Parmi les objets les plus remarquables, il faut mentionner une bague en or sur laquelle sont entaillés en pointillé deux noms en lettres grecques: celui d'un homme, "Madas", et celui d'une femme, "Psychè» (fig. 5); il faut également signaler une monnaie d'or de l'empereur romain Honorius (395-423), extrêmement bien conservée et d'un titre très élevé (999).

Chronologiquement, la très grande majorité des objets découverts dans les ensembles funéraires s'inscrivent dans la phase "classique» du site d'Ilouraton, à savoir la période comprise entre le I ${ }^{\text {er }}$ et le III siècle. Les tentatives de datation plus précises sont rendues difffciles par le fait que tous les caveaux funéraires étudiés, ainsi que la plupart des tombes, ont été pillés à une époque ancienne déjà, et beaucoup d'entre eux connurent une utilisation secondaire, d'où des confusions de mobilier de diverses époques.

Selon quelques observations, c'est à une phase plus ancienne, datant de la fin du $\mathrm{I}^{\mathrm{er}}$ ou du II $\mathrm{e}$ s. apr. J.-C., que se rapportent les aménagements funéraires voûtés: caveaux creusés dans la masse rocheuse et/ou faits d'une maçonnerie de moellons de calcaire, avec une voûte en berceau ou en encorbellement. Les hypogées en forme de grotte avec chambres funéraires et dromos, aménagés dans le rocher, datent probablement de la deuxième moitié du $\mathrm{II}^{\mathrm{e}}$ ou du $\mathrm{III}^{\mathrm{e}} \mathrm{s}$ s. apr. J.-C., et leur présence est à mettre en relation avec de nouvelles vagues de nomades (Sarmates d'une phase tardive?).

Au cours des fouilles sont apparus différents indices qui laissent supposer que la "vie» sur la nécropole méridionale se poursuivit après son abandon dans les années 260 . Kublanov date notamment le mobilier du caveau funéraire $\mathrm{n}^{\circ} 32 \mathrm{du}$ milieu du $\mathrm{IV}^{\mathrm{e}}$ siècle, et situe son utilisation 
secondaire, qui présente déjà des symboles chrétiens, au $\mathrm{V}^{\mathrm{e}}-\mathrm{VI}^{\mathrm{e}}$ siècle ${ }^{20}$. Et dans les restes de rituel funéraire étalés à proximité immédiate du caveau se trouvait du mobilier de la première moitié du $\mathrm{II}^{\mathrm{e}}$ siècle, potentiellement contemporain de sa construction ${ }^{21}$.

La monnaie d'or de l'empereur Honorius découverte lors des fouilles du caveau funéraire $\mathrm{n}^{\mathrm{o}} 18$ ne peut pas avoir atteint la nécropole avant la première moitié $\mathrm{du} \mathrm{V}^{\mathrm{e}}$ siècle.

Selon les observations de Kublanov, quelques anciennes constructions funéraires de la nécropole méridionale furent réutilisées dans les premiers siècles du Moyen Âge (VII ${ }^{e}-\mathrm{VIII}{ }^{\mathrm{e}}$ s.), et cela pour un autre rite funéraire, à savoir la crémation ${ }^{22}$. Le jalon chronologique le plus récent est fourni par une sépulture médiévale découverte dans l'horizon supérieur du remblai de comblement d'un hypogée, qui contenait quatre dirhams en argent frappés en Crimée et datant de l'an 665 de l'Hégire (1223 apr. J.-C.) ${ }^{23}$.

\section{La nécropole nord à inhumations en pleine terre}

Dans la partie nord-est du plateau, les fouilles de Kublanov donnèrent lieu en 1947 à la mise au jour du caveau funéraire $n^{\circ} 1$. Ainsi que l'ont montré les fouilles des années 1980-1990, c’est ici que se trouvait encore une nécropole à inhumations en pleine terre, au nord, occupant une superficie d'au moins 0,65 ha. Les recherches effectuées durant de nombreuses années ont fourni l'occasion de mettre au jour et d'étudier plus d'une centaine de complexes funéraires et commémoratifs qui avaient été pillés (constructions funéraires, sanctuaires et fosses sacrificielles, places de repas funéraires, sépultures de chevaux et de chiens). Les types de constructions funéraires se répartissent ainsi: 65 tombes en pleine terre, 24 tombes en dalles, 2 caveaux creusés dans le terrain et 3 caveaux à murs de moellons et dalles de calcaire. Dans leur très grande majorité, les tombes étaient orientées ouest-est (dans les tombes intactes, le défunt

20. M. M. Kublanov, «Novye pogrebal'nye sooruženija Ilurata» et «Raskopki nekropolja Ilurata", p. 110-112, 120-122.

2I. V. A. Khršanovskij, "Sklepy I - pervoj poloviny II vv. na Iluratskom plato", p. 404-406.

22. M. M. Kublanov, «Raskopki nekropolja Ilurata», p. 125.

23. Ibid. 


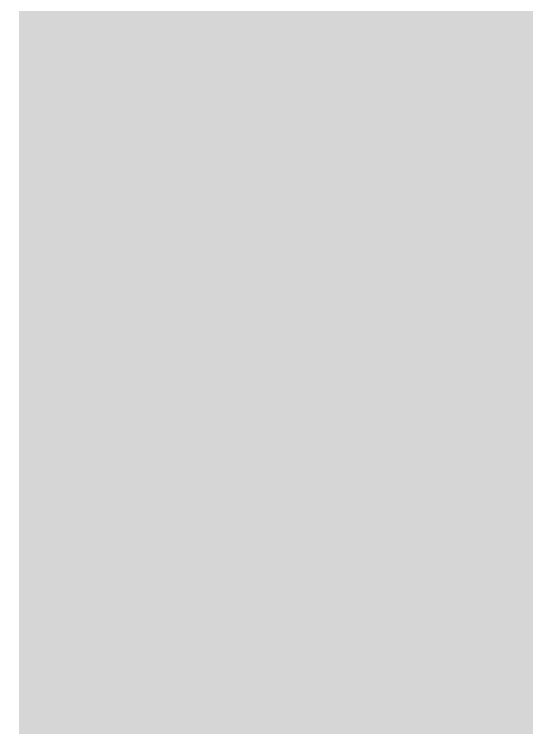

Fig. 6 - Nécropole nord à inhumations en pleine terre. Caveau $n^{\circ} 143$, creusé dans le terrain. Vue depuis l'est.

Photographie de Larisa Assel'. était étendu la tête tournée vers l'est).

Le mobilier mis au jour dans les tombes en pleine terre (vaisselle à vernis rouge, flacons à parfum en verre, fibules en bronze, ornements de collier en faïence égyptienne, perles de collier) permet une datation du $\mathrm{I}^{\mathrm{er}}$ ou du début du $\mathrm{II}^{\mathrm{e}}$ s. apr. J.-C. ${ }^{24}$. Sur les lieux de repas funéraires ont été découverts des fragments d'amphores plus anciennes, du $\mathrm{II}^{\mathrm{e}}-\mathrm{I}^{\mathrm{er}}$ s. av. J.-C. ${ }^{25}$.

Les dromos des caveaux funéraires aménagés dans la terre étaient orientés est/sud-est (du côté de la dépression du terrain à l'extrémité occidentale de laquelle ils ont été creusés) (n ${ }^{\text {os }} 143$ et 170 ), vers le sud $\left(n^{\circ} 1\right)$ et vers le nordouest (n०52).

Le caveau $\mathrm{n}^{\circ} 143$, situé sur le versant nord-ouest du terrain, a été mis au jour et étudié après avoir subi des pillages à l'époque contemporaine. Le dromos, taillé dans l'argile en place, menait à la baie d'entrée. Devant son seuil était posée une dalle de calcaire soigneusement taillée, mesurant 125 x $110 \mathrm{~cm}$, pour une épaisseur de 15 à $25 \mathrm{~cm}$. À en juger par sa situation, elle avait servi de dalle de fermeture (fig. 6). Son angle supérieur (sud-ouest) était cassé. Sur sa partie nord-ouest, occupant toute la largeur de la baie d'entrée, s'élevait un muret d'une à deux assises de pierres, d'une hauteur de $90 \mathrm{~cm}$ et d'une largeur de 35 à $85 \mathrm{~cm}$. Il était fait de pierres grossièrement taillées, de fragments de dalles de calcaire

24. M. M. Kublanov, V. A. Khršanovskij, «Nekropol' Ilurata», p. 8-27; V. A. Khršanovskij, «Pogrebal'no-pominal'nye kompleksy vtoroj poloviny I - pervoj poloviny II vv. n. è. na nekropole Ilurata".

25. V. A. Gorončarovskij, V. A. Khršanovskij, «Raskopki verkhnego nekropolja Ilurata». 
et d'un blocage de pierraille et de terre. Cette insertion témoigne incontestablement d'une utilisation secondaire du caveau.

La chambre funéraire, orientée comme le dromos suivant un axe sudest/nord-ouest, présentait un plan rectangulaire. Sa longueur était d'environ 3,4 m pour une largeur de 2,9 $\mathrm{m}$ et une hauteur, dans la partie conservée, d'au moins 1,3-1,4 m (contre les murs). Comme une grande partie du couvrement avait été détruite par des pillards et s'était effondrée, la hauteur d'origine ne peut qu'être supposée à partir du reste de voûte conservé dans la partie sud-est de la chambre funéraire.

Sur le sol de la chambre funéraire ont été découverts des fragments d'os d'un individu adulte (30-35 ans), ou éventuellement de deux (l'un étant vraisemblablement une femme), et d'un nouveau-né.

Des traces de bois décomposé dessinaient précisément les lignes parallèles de deux (ou trois?) cercueils. De nombreux débris de décors d'applique en plâtre (dauphins, tête de vache, fragment de masque) permettent de dater le caveau entre la fin du $\mathrm{I}^{\mathrm{er}}$ et le milieu du $\mathrm{II}^{\mathrm{e}} \mathrm{s}$. apr. J.-C. Parmi les autres objets découverts dans le caveau figurent des assiettes à vernis rouge (notamment à estampille in planta pedis et graffiti en forme de "tamga»), un petit vase (votif?) tourné en argile rouge, des fragments d'une cruche tournée et d'ustensiles en verre, des perles de collier, un anneau de bronze et des fragments d'objets en bronze, une agrafe de fer et des fragments d'objets du même métal, ainsi que des feuilles en tôle d'or d'une couronne funéraire. L'objet le plus ancien est une monnaie de bronze datant de 80-70 av. J.-C. (Paphlagonie pontique, Amissos [?] ; avers: tête de Persée casquée tournée vers la droite; revers: rongé par l'oxydation).

De menus fragments d'os humains appartenant à plusieurs adultes et à un enfant, découverts dans la terre de remplissage du dromos, témoignent peut-être d'un pillage du caveau ou de son déblaiement en vue d'une réutilisation.

Les objets mis au jour dans le dromos ne sont pas nombreux: débris d'un pot modelé, fragment d'un vase à vernis brun à entailles, tout petit reste d'une feuille d'or, débris d'épées en fer, silex et fragments de décors d'appliques en plâtre.

Le matériel archéozoologique, consistant essentiellement en ossements d'animaux domestiques et de divers oiseaux, est vraisemblablement à mettre en rapport avec le repas funéraire plutôt qu'avec la chambre funéraire. 
Dans le dromos a été mise au jour une tombe secondaire. Sa disposition et surtout sa datation ( $\mathrm{II}^{\mathrm{e}} \mathrm{s}$. apr. J.-C.) attestent une réutilisation simultanée du caveau. Par conséquent, l'époque de l'aménagement du caveau funéraire et de sa première utilisation peut être fixée au $\mathrm{I}^{\mathrm{er}}$ ou à la première moitié du II siècle $^{26}$.

Les tombes en dalles et les caveaux en blocs et en dalles de calcaire aménagés dans le secteur nord-est se réfèrent à une époque un peu plus tardive que les inhumations en pleine terre. Le plus important d'entre eux est le caveau $\mathrm{n}^{\circ} 52$ (dromos 2,6 x 1,1-1,4 m, chambre funéraire $3 \times$ $5 \mathrm{~m}$ ). Les murs ont été retrouvés complètement démolis et il n'est plus possible de savoir de quel type était la voûte qui couvrait le caveau. Les limites de la chambre funéraire sont définies par l'extension du pavage du sol.

Le mobilier découvert dans ce caveau a été daté des $\mathrm{II}^{\mathrm{e}}$-III ${ }^{\mathrm{e}} \mathrm{s}$. apr. J.-C. Quelques indices permettent de supposer que la construction du caveau a touché et perturbé toute une série d'inhumations en pleine terre plus anciennes, datant de la fin du ${ }^{\mathrm{er}}$ au début du $\mathrm{II}^{\mathrm{e}}$ s. apr. J.-C. ${ }^{27}$. Dans une dernière phase, déjà postérieure à la démolition du caveau, au III $^{\mathrm{e}}-\mathrm{IV}^{\mathrm{e}}$ siècle, l'endroit servit pour des repas funéraires. On peut donc ainsi situer l'époque de construction et d'utilisation du caveau entre la première moitié du $\mathrm{II}^{\mathrm{e}}$ et la première moitié du $\mathrm{III}^{\mathrm{e}}$ siècle.

Tout le terrain adjacent à l'ouest du caveau no 52 présentait une aire rituelle avec des vestiges de repas funéraires (taches cendreuses, entassement de tessons de céramique, os d'animaux déposés à part, sépultures de chevaux et de chiens). Les objets déposés en offrandes sont, à de rares exceptions près, de nature similaire à ceux rencontrés sur les lieux rituels du secteur sud: fragments d'un vase de transport en céramique, tessons de céramique à vernis rouge, débris de poterie tournée et modelée et de vaisselle de verre (en partie fondu), lampes en argile, fragments de statuettes rituelles en terre cuite à jambes et phallus suspendus (principalement des jambes et des têtes). La plupart de ces objets, ainsi que le mobilier provenant du caveau lui-même datent d'entre la fin du $\mathrm{II}^{\mathrm{e}}$ et la première moitié du III ${ }^{\mathrm{e}}$ siècle. Certains, beaucoup plus anciens (fragments de "bols mégariens", céramique à paroi fine et vernis rouge avec décor à la barbotine) peuvent provenir des sépultures en pleine terre

26. N. V. Zakharenkov, "Gruntovyj sklep I v. n. è. na nekropole Ilurata».

27. M. M. Kublanov, V. A. Khršanovskij, «Nekropol’ Ilurata», p. 8-18. 


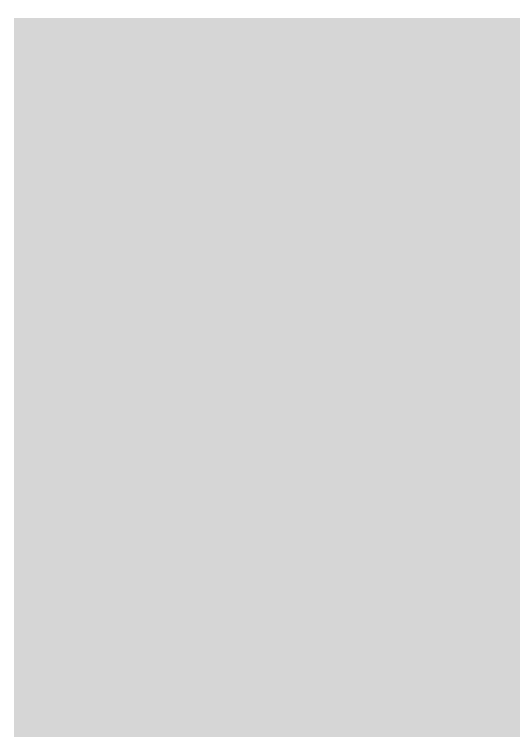

Fig. 7 - Nécropole nord à inhumations en pleine terre. Place de repas funéraire près du caveau $\mathrm{n}^{0} 52$. Statuette de terre cuite. Photographie de Larisa Assel'.

détruites lors de la construction du caveau et avoir abouti dans la couche du repas funéraire, ou bien avoir été apportés spécialement pour une utilisation dans l'accomplissement de ce rite.

Au nombre des découvertes exceptionnelles de ce complexe compte assurément une statuette de déesse grecque en terre cuite, cassée en grands morceaux; avec ses $62 \mathrm{~cm}$ de hauteur, ce chefd'œuvre de la coroplastie antique est la plus grande statuette de terre cuite trouvée sur les rives septentrionales de la mer Noire (fig. 7). Elle peut dater du $\mathrm{I}^{\mathrm{er}}-\mathrm{II}^{\mathrm{e}}$ s. apr. J.-C. Des analogies iconographiques permettent de la rapprocher de l'Aphrodite de Kèpoi et des figures de Tychè ${ }^{28}$.

Dans les intervalles entre les tombes, près des inhumations en pleine terre, ont été découvertes quelques fosses sacrificielles creusées dans le terrain naturel, contemporaines et formant avec les tombes un ensemble funéraire et commémoratif cohérent ${ }^{29}$. De même que dans le secteur sud, en plus des tombes, on a également mis au jour ici quelques sépultures connexes de chevaux et de chiens.

Dans un article dressant le bilan des recherches des années 19601970, Kublanov a supposé que c'est dans le secteur nord, le plus proche de la ville, près du caveau $\mathrm{n}^{\circ} 1$, que se trouvent les inhumations les plus anciennes, que les rites funéraires y sont ceux d'une autre tradition ethnoculturelle que dans le secteur sud, et même qu'à l'origine, les secteurs nord et sud étaient «les nécropoles séparées de deux ethnies différentes

28. V. A. Gorončarovskij, «Terrakotovaja statuja ženskogo božestva iz raskopok nekropolja Ilurata».

29. V. A. Khršanovskij, "Gruntovye žertvennye jamy na nekropole Ilurata». 
établies à Ilouraton ${ }^{30}$. Les investigations archéologiques menées ensuite sur le site ont confirmé cette hypothèse.

Avec une quantité de mobilier de type et de date similaires, la nécropole occupant le secteur nord-est du plateau d'Ilouraton se distingue un peu de celle du secteur sud, à tombes creusées dans la roche, et de celle du secteur sud-ouest. C'est ici qu'ont été mis au jour les objets les plus anciens, datant environ du début de l'ère chrétienne: fragments de céramique à paroi fine et vernis rouge avec décors à la barbotine et traces de peinture de couleur blanche, d'amphores à anses bifides, ainsi qu'une monnaie pontique du ${ }^{\mathrm{er}}$ s. av. J.-C. Lors des fouilles sont apparus des objets de l'époque hellénistique: fragments de terre cuite, d'amphores, de «bols mégariens» et de vaisselle à vernis noir. En revanche, les armes (épées, pointes de flèche) y sont plus rares dans les sépultures et l'on n'y recense ni miroir "sarmate» - à une seule exception près - ni crânes portant des traces de déformation du vivant de l'individu. Il n'est pas exclu que, comme le supposait Kublanov, cette nécropole plus ancienne soit à rattacher à une tradition ethnoculturelle différente, quoique apparentée.

Il faut faire remarquer qu'ici, tout comme dans la nécropole sud, on trouve des traces de pillages anciens des caveaux funéraires, qui sont ensuite réutilisés pour une autre sépulture ou comme place rituelle.

\section{La nécropole sud-ouest à inhumations dans la roche et en terre}

Les recherches archéologiques effectuées à la fin des années 1990 et dans les années 2000-2010 (ainsi que les investigations complémentaires après les pillages contemporains) sur le plateau d'Ilouraton, à l'ouest et au nord-ouest de la nécropole méridionale à tombes taillées dans la roche, ont amené à la mise au jour d'un nouveau secteur de la nécropole (ou d'une nécropole distincte), qui s'étend sur l'extrémité sud du plateau, entre deux hauteurs rocheuses et occupant une partie de l'extrémité ouest, sur une superficie de 4 ha au minimum (les limites précises n'ont pas été repérées). En plus de 22 inhumations en pleine terre et de 11 tombes à dalles ont été ouverts, étudiés et réexaminés après les pillages récents: 4 hypogées taillés dans la roche ( $\mathrm{n}^{\text {os }} 215,216,218$ et 222), 3 caveaux creusés dans la roche ( $n^{\text {os }} 160,180$ et 211$)$ avec une

30. M. M. Kublanov, «Raskopki nekropolja Ilurata», p. 128 sq. 
voûte maçonnée qui peut avoir été en berceau ou en encorbellement et 5 caveaux construits en moellons de calcaire et vraisemblablement couverts d'une voûte en berceau: deux relativement petits ( $n^{\text {os }} 205$ et 206) et trois monumentaux ( $\mathrm{n}^{\text {os }} 213,220$ et 225 , avec les cénotaphes $n^{\text {os }} 226$ 227) ${ }^{31}$.

Entre les hauteurs sud et sud-ouest du plateau d'Ilouraton, le massif rocheux était recouvert d'une importante épaisseur de terre dans laquelle se trouvait la très grande majorité des tombes en pleine terre et à dalles étudiées après le passage des pillards. La plupart d'entre elles ont été pillées dans les années 1990, et quelques-unes peut-être déjà à une époque ancienne. Pour la moitié des tombes environ, l'orientation dominante est clairement ouest-est. Pour les autres, elle se rapproche du sud. Le mobilier funéraire conservé donne une large fourchette chronologique entre le II e et le III ${ }^{\mathrm{e}}$ s. apr. J.-C.

À l'extrémité sud-ouest du plateau, on a découvert et étudié quatre hypogées d'un type particulier ( $\mathrm{n}^{\text {os }} 215,216,218$ et 222), pillés à une époque ancienne. Ils se distinguent par leurs grandes dimensions, en comparaison avec les hypogées du secteur sud (à l'exception de l'hypogée $\left.n^{\circ} 19\right)$. Tous sont orientés nord-sud, avec l'entrée au sud.

Dans le plus grand d'entre eux ( $\left.{ }^{\circ} 215\right)$, le dromos présente une longueur d'environ $1,5 \mathrm{~m}$, pour une largeur d'environ $2 \mathrm{~m}$. La chambre funéraire a une surface d'environ $15 \mathrm{~m}^{2}$ (5,85 x 2-2,6 m).

Dans la chambre funéraire ont été découvertes les sépultures de deux chevaux. Les nombreux fragments d'épées et de mors recueillis dans les tombes laissent penser qu'il y avait des cavaliers parmi les défunts.

Un ensemble de vaisselle à vernis rouge et décor à la barbotine, une œnochoé en verre et une cruche à vernis noir brillant amènent à dater cet hypogée, comme les trois voisins, de la deuxième moitié du $\mathrm{II}^{\mathrm{e}}$ ou du début du III ${ }^{\mathrm{e}}$ siècle $^{32}$.

Il n'est pas sans intérêt de noter la découverte, dans la couche supérieure de l'hypogée voisin $n^{\circ} 216$, d'une sépulture de cavalier (XII ${ }^{\mathrm{e}}$ début du XIII ${ }^{\mathrm{e}}$ siècle) que les étriers de fer et les appliques figurées en

3I. V. A. Khršanovskij, "Sklepy I - pervoj poloviny II vv. na Iluratskom plato», p. 386-405 et «Sklepy-katakomby na Iluratskom plato», p. 531-543.

32. Ibid., p. 535-543. 
Fig. 8 - Pierre en forme d'obélisque peinte d'un signe sarmate. Caveau n ${ }^{\circ} 160$. Photographie de Larisa Assel'. os trouvés là permettent de rattacher à la culture nomade des Bonnets noirs (Berindei, Torks, Petchénègues) ${ }^{33}$.

Au nord-ouest de la ceinture que forment les hypogées ont été mis au jour et fouillés trois caveaux funéraires creusés dans la roche ( $\mathrm{n}^{\text {os }} 160,180$ et 211$)$. Ils se trouvent tous à l'extrémité occidentale du plateau et sont orientés avec l'entrée du côté du couchant.

\section{Le caveau $\mathrm{n}^{\mathrm{O}} 160$}

Orienté sud-ouest/nord-est, il se distingue des aménagements funéraires du même type par un mode de construction inhabituel, par la présence d'une fosse sacrificielle avec des vestiges de repas funéraires et quelques objets peu ordinaires. Il comprend une chambre, un dromos et un "prodromos». La chambre funéraire, de plan rectangulaire, mesure $5 \mathrm{~m}$ de long pour 2,83-2,85 $\mathrm{m}$ de large. Depuis le sudouest, un dromos également taillé dans le rocher mène à l'entrée de la chambre funéraire. De plan presque parfaitement rectangulaire, ce dromos avait une longueur de 1,35-1,45 m pour une largeur de 1,80$1,85 \mathrm{~m}$ (il allait en rétrécissant en direction de l'entrée). Le sol du dromos (qui était la roche aplanie) se situait 3-5 cm plus bas que le seuil qui le séparait de la chambre funéraire. Au milieu du dromos, à même le sol, était posée à plat une pierre en forme de pyramide irrégulière ("obélisque" ?), longue de $63 \mathrm{~cm}$, dont une des faces montrait un signe sarmate tracé à la peinture rouge (fig. 8). Un "prodromos» formant une rampe menait au dromos. Les pierres et les moellons découverts là avaient été équarris sur place et peuvent être les restes d'un escalier.

33. V. A. Khršanovskij, «Nekropol’ bez akropolja (nekropol' Ilurata v IV-XIII vv. n. è.)", p. 345 . 
Le mobilier découvert dans la chambre du caveau se répartit dans une fourchette chronologique assez large. Pour le $\mathrm{I}^{\mathrm{er}}$ et le $\mathrm{II}^{\mathrm{e}}$ siècle, on recense un fragment de fond d'assiette à vernis rouge et estampille in planta pedis, une châsse de bijou en cornaline avec une gemme représentant un oiseau (corbeau ?) sur une branche, une pendeloque en verre transparent bleu foncé en forme de petit vase stylisé, de nombreuses perles (notamment en agate et en faïence égyptienne), un fragment de petite fibule à volute à l'extrémité du porte-ardillon. En plus de ces objets ont également été découvertes des assiettes à vernis rouge, une lampe en argile rouge à décor en relief sur la circonférence et une grande fibule de bronze $(6,7 \mathrm{~cm})$, qui sont tous à situer chronologiquement au III ${ }^{\mathrm{e}}$ siècle. Les pointes de flèche en fer à trois ailerons datent du $\mathrm{II}^{\mathrm{e}}$ au $\mathrm{IV}^{\mathrm{e}}$ siècle. Un ornement de collier en or de forme biconique trouve des exemples similaires dans des ensembles encore plus tardifs, du III et du début du IV siècle.

La fouille du dromos n'a pas livré beaucoup de mobilier. En plus de la pierre au signe sarmate déjà décrite, il s'agit de tessons d'amphores (amphores en argile claire du sud de la région pontique, amphores bosporanes en argile rouge et rose) et de céramique tournée et modelée, ainsi que de fragments de verre. Les éléments d'amphores datables (principalement des anses et des lèvres en forme de corolle d'amphores à col étroit) se répartissent entre la fin $\mathrm{I}^{\mathrm{er}}$-début $\mathrm{II}^{\mathrm{e}} \mathrm{s}$. apr. J.-C. et la fin $\mathrm{II}^{\mathrm{e}}$ début III ${ }^{\mathrm{e}}$ siècle. Les coupes à vernis rouge datent du $\mathrm{II}^{\mathrm{e}}-\mathrm{III}^{\mathrm{e}}$ siècle. On n'a pas trouvé là de signe sarmate. C'est de cette époque également que datent les éléments graphiques constituant l'inscription.

Quelques fragments de panses d'amphores à inscriptions peintes et graffiti ont été mis au jour lors des fouilles du dromos. Un tesson d'amphore en argile brun clair avec des inclusions de couleur blanche, quelques rares paillettes de mica et un enduit clair sur lequel était conservée une partie des inscriptions à la peinture rouge a particulièrement attiré l'attention. Tous ces indices laissent supposer qu'il s'agit d'une amphore de Chios, et par conséquent de l'un des plus anciens objets découverts dans la nécropole d'Ilouraton. Un petit nombre de fragments de ce type (sans inscriptions peintes), provenant peut-être tous de la même amphore, ont encore été découverts. Des traces de couleur rouge (également un reste de signes peints au pinceau?) ont aussi été observées sur une panse d'amphore bosporane en argile brun foncé. 
Une panse d'amphore bosporane en argile rouge présentait en graffiti le chiffre romain «XI».

La fouille du caveau $\mathrm{n}^{\circ} 160$ a fait apparaître les restes des ossements d'au moins 28 adultes et d'au moins 4 enfants.

La terre de remplissage du caveau funéraire contenait encore des ossements d'animaux: une génisse, un saïga (?), un cheval adulte, une chèvre adulte, cinq moutons ou béliers adultes, un chien adulte et un jeune chien, des os de lièvre et d'oiseau. Il n'est pas inintéressant de noter que plusieurs os d'animaux avaient été rongés par un chien, ce qui prouve qu'ils étaient restés un certain temps à l'air libre.

À une distance de 40 à $95 \mathrm{~cm}$ au sud-ouest du commencement du "prodromos", 5 à $15 \mathrm{~cm}$ plus bas que le bord taillé du rocher, a été mise au jour une fosse sacrificielle recouverte de pierraille. Les pierres les plus volumineuses étaient disposées sur la périphérie, marquant la circonférence et délimitant l'espace où s'était tenu le repas funéraire. En plan, la fosse présentait une forme d'ovale irrégulier (allongé du sud-est vers le nord-ouest, mais avec un décalage vers l'est et l'ouest). Elle avait une longueur de 2,5 m dans la partie supérieure, pour une largeur de 1,5 à 1,7 m. Pour le ou les repas funéraires, le sol avait été creusé à une profondeur de 65-70 $\mathrm{cm}$ depuis le bord supérieur du rocher. Le fond de la fosse était formé par la roche non aplanie. Dans l'angle sud-ouest, la roche était percée d'ouvertures en forme d'ovales irréguliers de 20 à $30 \mathrm{~cm}$ de diamètre.

Dans le remplissage de la fosse, l'épaisseur de la couche supérieure de pierraille atteignait $20 \mathrm{~cm}$. En dessous se trouvait une couche de terre argileuse d'une épaisseur de 12 à $16 \mathrm{~cm}$. Plus bas ont été découverts les débris d'une amphore bosporane en argile rose sans fond, qu'une couche de pierres séparait encore de nombreux fragments de céramique déposés au fond de la fosse, à même la roche.

Dans les restes laissés par le repas funéraire, les amphores sont nettement dominantes: amphores bosporanes en argile rose (fin du $\mathrm{II}^{\mathrm{e}}$ ou III siècle) et en argile rouge, amphores des régions pontiques méridionales en argile claire. Mais on a également découvert de la céramique tournée et de la céramique modelée. Dans la couche inférieure de la même fosse ont cependant été prélevés aussi un pied et une anse d'amphore en argile claire à col étroit de datation plus ancienne (fin du $\mathrm{I}^{\mathrm{er}}$ début du II ${ }^{\mathrm{e}}$ siècle). Je reprendrais cette phrase comme suit: Les coupes à vernis rouges de cet ensemble (avec appliques en forme de nœuds) datent quant à elles du II ${ }^{\mathrm{e}}$ siècle. 
La répartition chronologique du mobilier découvert permet de supposer que le rite du repas funéraire a été accompli au moins deux fois. D'abord dans la première moitié du $\mathrm{II}^{\mathrm{e}}$ siècle, avec utilisation de fragments d'amphores des régions pontiques méridionales en argile claire, d'amphores bosporanes en argile rouge, de céramique à vernis rouge et de céramique modelée, le tout découvert essentiellement dans la couche inférieure. Puis à la fin du $\mathrm{II}^{\mathrm{e}}$ ou au III ${ }^{\mathrm{e}}$ siècle, avec une amphore bosporane en argile rose provenant de la couche supérieure de la fosse sacrificielle.

Le matériel ostéologique se limite ici à un fragment de métacarpe de cheval et quelques fragments non identifiables d'os d'un petit animal.

La chronologie du caveau funéraire et celle de la fosse sacrificielle sont ainsi entièrement concordantes, et cet ensemble funéraire et commémoratif a été utilisé au moins deux fois: à la fin du $\mathrm{I}^{\mathrm{er}}$ ou au début du $\mathrm{II}^{\mathrm{e}}$ siècle, puis à la fin du $\mathrm{II}^{\mathrm{e}}$ ou au III ${ }^{\mathrm{e}}$ siècle $^{34}$.

Le caveau funéraire $\mathrm{n}^{\circ} 211$

Situé à l'extrémité sud-ouest du plateau rocheux, bien connu par les fouilles de la nécropole sud, il était creusé dans le rocher et comprenait une chambre funéraire rectangulaire $(2 \times 2,5 \mathrm{~m})$ et un dromos de faible longueur (env. $1 \mathrm{~m}$ ), menant à la chambre depuis l'ouest.

Le caveau avait été pillé à une époque ancienne et sa voûte détruite. La terre de remplissage a livré divers objets: une assiette à vernis rouge entière (archéologiquement) avec des graffiti, des perles d'agate et de verre, des fragments de fibules et de bagues en bronze, quelques os. Ce mobilier se répartit sur une période assez large, du Ir au III ${ }^{\mathrm{e}}$ siècle. Dans l'angle nord-est du caveau a cependant été mise au jour une fosse creusée dans le massif rocheux, de plan presque carré $(1 \times 1 \mathrm{~m}, 70 \mathrm{~cm}$ de profondeur), recouverte d'une dalle de calcaire intacte. Cet ensemble clos contenait, outre des ossements humains (principalement d'enfants), divers objets auxquels on attribue traditionnellement une datation beaucoup plus ancienne (fin du $\mathrm{I}^{\mathrm{er}}$ ou première moitié du $\mathrm{II}^{\mathrm{e}}$ siècle) : ornement de collier en forme de scarabée en faïence égyptienne, perles d'agate et de verre, boucle d'oreille en bronze. Il est possible que la fosse

34. V. A. Khršanovskij, «Pogrebal'nyj kompleks rimskogo vremeni na nekropole Ilurata». 


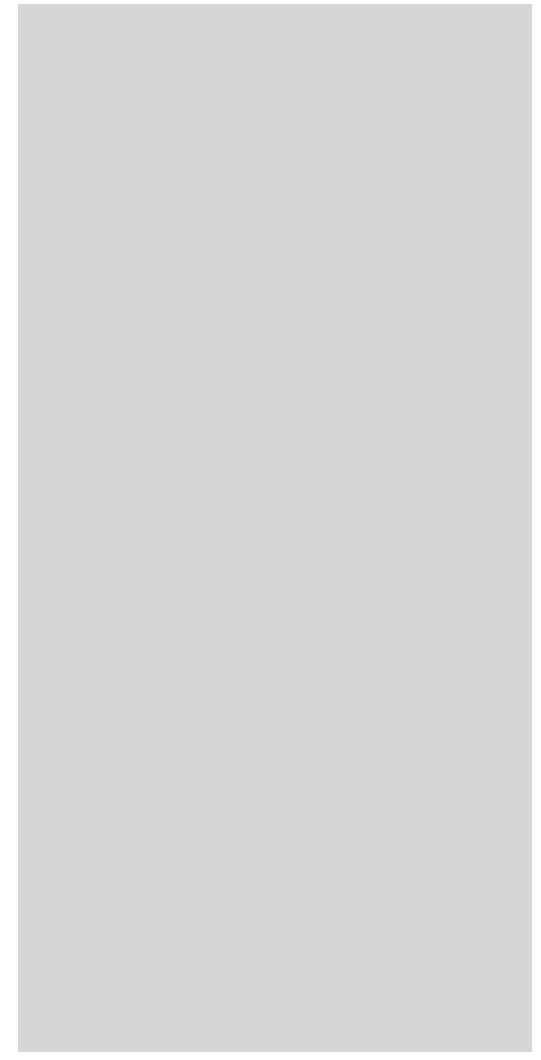

Fig. 9 - Artefact en os avec dessins gravés sur ses quatre facettes (calendrier?). Caveau n ${ }^{\circ} 211$. Photographie de Larisa Assel'. ait été creusée (ou utilisée) pour le ré-enfouissement des restes des premiers défunts enterrés ici ${ }^{35}$.

Parmi les découvertes inhabituelles de cet ensemble funéraire figure un petit artefact en os à quatre facettes, avec des dessins gravés sur chacune d'entre elles (fig. 9). Toutes les facettes sont divisées en champs rectangulaires par des lignes verticales nettes. La surface de chaque champ est à son tour divisée en quatre triangles par une croix oblique (parfois tracée avec négligence ou juste suggérée). L'intérieur de certains triangles montre des lunules très précisément gravées. Les facettes montrant une alternance régulière de formes répétitives, on peut supposer que cet objet avait une destination fonctionnelle particulière et qu'il s'agit peut-être d'un calendrier bosporan ${ }^{36}$.

Cinq caveaux funéraires $\left(\mathrm{n}^{\text {os }} 205,206,213,220,225-227\right)$

Formant un groupe à part, ils sont construits en moellons et dalles de calcaire. Dans quatre d'entre eux, le dromos est tourné vers le sud, alors que le cinquième $\left(\mathrm{n}^{\circ} 206\right)$ regarde vers l'ouest. Les caveaux les plus anciens, qui sont aussi plus monumentaux ( $\left.\mathrm{n}^{\text {os }} 213,220,225-227\right)$,

35. V. A. Khršanovskij, «Sklepy I - pervoj poloviny II vv. na Iluratskom plato», p. 381-385.

36. N. V. Moleva, I. A. Tul'pe, V. A. Khršanovskij, «Kostjanaja podelka iz Ilurata bosporskij kalendar'?». 
datent de la deuxième moitié du $\mathrm{I}^{\text {er }}$ siècle ou de la première moitié du $\mathrm{II}^{\mathrm{e}}$ siècle. Les caveaux de moindres dimensions ( ${ }^{\text {os }} 205$ et 206) sont vraisemblablement plus récents, de la deuxième moitié du $\mathrm{II}^{\mathrm{e}}$ ou du début du III siècle. Tous les caveaux ont été pillés au moins deux fois, à une époque ancienne et à notre époque. La plupart ont connu une réutilisation dans l'Antiquité tardive ou au haut Moyen Âge à des fins de sépulture et/ou d'actes rituels.

Le mobilier récolté lors de l'examen des tombes pillées en terre et en dalles ${ }^{37}$ et des deux caveaux funéraires de moindres dimensions (le $\mathrm{n}^{\circ} 205$ avec une chambre funéraire d'une superficie d'environ $6 \mathrm{~m}^{2}$ et le $\mathrm{n}^{\circ} 206$ avec une voûte en berceau et une chambre funéraire de $9 \mathrm{~m}^{2}$ environ ${ }^{38}$ ), comprend des tessons d'amphore à profil, de la vaisselle en céramique à vernis rouge et en verre, des fragments de flacons à parfum en verre, un hochet en terre cuite, une lampe en argile, des bracelets et des perles de collier en bronze. Ce mobilier peut être sommairement daté de la deuxième moitié du $\mathrm{II}^{\mathrm{e}}$ ou du $\mathrm{III}^{\mathrm{e}}$ siècle. Ici, comme dans les autres nécropoles, une sépulture de cheval a été découverte près de la tombe $\mathrm{n}^{\circ} 106$ et dans le caveau $\mathrm{n}^{\circ} 206$ des restes d'actes rituels ont été mis en évidence - peut-être plus tardifs (IV ${ }^{\mathrm{e}}$ siècle?) - avec immolation d'animaux sauvages et domestiques: cheval, vache, mouton, bélier et lièvre.

Trois très grands caveaux funéraires voûtés ( $\mathrm{n}^{\text {os }} 213,220$ et 225), situés dans la partie nord-ouest de la nécropole à inhumations en pleine terre, au pied de l'élévation rocheuse, méritent une attention particulière ${ }^{39}$.

Les trois caveaux étaient couverts d'une voûte en berceau et orientés exactement selon l'axe nord-sud, avec le dromos tourné vers le sud.

Le caveau $n^{\circ} 213$

Fait d'une maçonnerie de moellons et de dalles de calcaire assemblés à sec, il comprenait une chambre funéraire rectangulaire $(5 \times 3,85 \mathrm{~m})$, un dromos qui y conduisait depuis le sud (3,6 x 1,85-2 m) et, aménagée à

37. M. M. Kublanov, V. A. Khršanovskij, «Nekropol’ Ilurata», p. 36-40.

38. V. A. Khršanovskij, "Novyj sklep s polucirkul'nym svodom na nekropole Ilurata».

39. V. A. Khršanovskij, "Sklepy I - pervoj poloviny II vv. na Iluratskom plato», p. 386-405. 
Fig. 10 - Nécropole sud-ouest de type mixte. Caveau $n^{\circ} 213$. Vue depuis le sud. Photographie de Larisa Assel'.

l'intérieur du mur de front de la chambre funéraire, une niche $(1,35 \mathrm{x}$ $1 \mathrm{~m})$ couverte d'un arc en berceau entièrement conservé. La longueur totale de cette construction, depuis la première marche du dromos jusqu'au mur du fond de la niche, était de 10,2 m (fig. 10).

On accédait au dromos par cinq marches en blocs de calcaire soigneusement taillés, formant des parallélépipèdes d'une longueur de 1,0-1,1 m (marche supérieure) à 1,3-1,4 m (marche inférieure). La différence de niveau, dans le dromos, entre la marche supérieure et le pavage du sol était de $1,5 \mathrm{~m}$.

Au niveau de la marche inférieure se trouvait, posée à plat, une dalle de calcaire soigneusement taillée, en forme de rectangle régulier (1,9$1,95 \times 1,3-1,35 \mathrm{~m}$, pour une épaisseur de $15 \mathrm{~cm}$ ), fendue en trois parties. Ses dimensions et son emplacement laissent supposer qu'elle avait servi à fermer la baie d'entrée donnant du dromos dans la chambre funéraire.

Les parois du dromos avaient un parement de gros moellons équarris présentant une face dressée. La hauteur conservée des murs était de 1,10$1,25 \mathrm{~m}$. 
Le sol de la chambre funéraire était pavé de dalles de calcaire en forme de rectangles réguliers (dimensions de 0,30 x $0,60 \mathrm{~m}$ à $0,55 \times 1,25 \mathrm{~m}$, épaisseur 6 à $8 \mathrm{~cm}$ ).

Le mur arrière (nord) de la chambre funéraire, conservé sur une hauteur de 1,7-1,9 m, présentait un aspect inhabituel. Au milieu était habilement aménagée une niche d'une largeur de $2 \mathrm{~m}$ et d'une profondeur de 1,10-1,15 m, couverte d'une voûte en berceau dont la flèche mesure $1 \mathrm{~m}$. La face d'entrée de la voûte, à l'ouest de la clef, montrait un graffiti dont la forme rappelle le $\lambda$ grec.

Derrière le mur oriental de la chambre funéraire du caveau $\mathrm{n}^{\circ} 213$ (angle nord-ouest), depuis le côté extérieur, s'ouvrait une cachette en pierre $(1,4 \times 1,1 \mathrm{~m}$, pour une profondeur de $60 \mathrm{~cm})$ remplie d'os d'animaux et d'oiseaux. L'analyse archéozoologique a établi la présence de squelettes de deux chiens adultes (un sans le crâne et vraisemblablement d'une femelle), des restes osseux d'un jeune lièvre et d'un lièvre adulte, d'un jeune chat, d'un chat subadulte et d'un chat adulte, d'un oiseau (chouette chevêche) et d'au moins trois chauves-souris.

Les os de tous ces animaux n'ont révélé aucune trace d'abattage, de découpe au couteau, de démembrement, d'écorchement ni de morsures par des dents de chien.

L'inventaire des restes osseux d'animaux et d'oiseaux découverts dans la cachette (à l'exclusion peut-être des chauves-souris), leur charge sémantique spécifique, la constance des correspondances intraspécifiques (individu vieux ou adulte - individu jeune) permettent de supposer que leur présence à tous résulte d'un acte délibéré, d'une offrande rituelle à laquelle, si l'on en juge par l'ensemble, cette cachette était destinée dès le début.

Le caveau funéraire avait été détruit et pillé à une époque ancienne. Le mobilier découvert, très peu abondant (fragments profilés d'amphores, de céramique à vernis rouge et de vaisselle de verre, perles de bronze et de verre), peut être sommairement daté du $\mathrm{I}^{\mathrm{er}}$-II e s. apr. J.-C.

Plusieurs panses de poteries en argile rouge montrent des graffiti en forme de croix obliques ou de courtes lignes. Un fragment de panse d'amphore en argile rouge est d'un intérêt particulier: il présente en effet une série de signes en forme de tamgas, constituant une espèce "d'encyclopédie de tamgas". 
Fig. 11 - Nécropole sud-ouest de type mixte. Caveau no 213 . Anneau d'or à grenats. Photographie de Larisa Assel'.

Une grande fibule en bronze $(7 \mathrm{~cm})^{40}$, découverte dans la couche supérieure de la chambre funéraire, donne une datation beaucoup plus serrée: par comparaison avec des modèles très similaires, elle peut être datée de la première moitié ou du milieu du II s. apr. J.-C.

Un fragment de couronne funéraire en feuille de métal jaune témoigne de l'antique richesse du mobilier funéraire déposé auprès du défunt (ou des défunts) dans le caveau. Un autre objet encore, trouvé dans l'angle sud-est, dans la couche qui recouvrait le sol, est en adéquation avec les dimensions et la qualité de cet aménagement funéraire: un anneau déformé en métal jaune, à décor en filigrane ajouré et grenats, remarquable produit de l'orfèvrerie bosporane, datant du milieu du II ${ }^{\mathrm{e}}$ siècle au plus tard (fig. 11) ${ }^{41}$.

Au sud/sud-est du dromos a été mise au jour une petite aire sacrificielle pour repas funéraire, comme en témoignent de nombreux fragments de céramique tournée et modelée, des débris fondus de vaisselle de verre, des objets en fer et en bronze. La découverte la plus remarquable est celle d'une partie de médaillon en forme de masque (tête de Déméter), qui formait le fond décoré d'une poterie à vernis rouge. Les fragments profilés de vaisselle de verre, de coupes à vernis rouge et de "plats à poissons" permettent de dater le repas funéraire du III" siècle.

\section{Le caveau $n^{\circ} 220$}

Situé à environ $50 \mathrm{~m}$ au nord du caveau $\mathrm{n}^{\circ} 213$, comme celui-ci, il était fait de moellons et de dalles de calcaire et présentait une orientation

40. Fibule à ressort quatre spires et corde externe, à arc filiforme et à pied fixé par enroulement.

4I. N. V. Zakharenkov, V. A. Khršanovskij, M. Ju. Trejster, «Vydajuščijsja pamjatnik pogrebal'noj arkhitektury nekropolja Ilurata»; V. I. Mordvinceva, M. Ju. Trejster, Proizvedenija torevtiki i juvelirnogo iskusstva $v$ Severnom Pričernomor'e $2 v$. do n. è- $2 v$. n. è., no A93a1, t. 2, p. 35; t. 3, pl. 4. 
Fig. 12 - Nécropole sud-ouest de type mixte. Caveau nº 220 . Vue depuis le nordouest. Photographie de Larisa Assel'. 
très exactement au sud. À la différence du no 213 cependant, il comprenait un dromos et deux chambres funéraires (fig. 12). Le dromos (4,5 x 1,0-1,2 m; murs conservés jusqu'à 2,5 m) menait depuis le sud vers une petite chambre funéraire de plan presque carré $(3 \times 3,5 \mathrm{~m})$. Cette chambre était séparée du dromos par une dalle de fermeture verticale encore in situ, fixée depuis l'intérieur à l'aide de moellons de calcaire lors de la réutilisation de la chambre funéraire. Plus spacieuse, la seconde chambre funéraire présente un plan rectangulaire $(5 \times 3,6 \mathrm{~m})$. Les murs étaient conservés sur une hauteur de 1,7 m. Dans les deux chambres, le sol était pavé de dalles de calcaire. Les moellons à douelle trouvés dans le remblai de comblement amènent à supposer que les deux chambres funéraires étaient couvertes d'une voûte en berceau.

$\mathrm{Au}$ cours des fouilles, on a distingué provisoirement quatre phases chronologiques:

1) période de la construction du caveau funéraire et de sa première utilisation (milieu ou deuxième moitié du $\mathrm{II}^{\mathrm{e}}$ s. apr. J.-C.) ;

2) période de la démolition de la grande chambre funéraire et d'inhumations collectives (plus de 15 individus) dans la petite chambre funéraire (fin du $\mathrm{II}^{\mathrm{e}}-\mathrm{III}{ }^{\mathrm{e}}$ siècle) ;

3) inhumation, dans la partie orientale de la petite chambre funéraire (dans la couche au-dessus de l'amoncellement des ossements humains et animaux du niveau précédent), d'une jeune femme au crâne déformé de son vivant, accompagnée d'une sépulture de chien (III ${ }^{\mathrm{e}}$-début du IV ${ }^{\mathrm{e}}$ siècle) ;

4) dernière utilisation du caveau funéraire, liée à l'accomplissement de rites, correspondant à la couche supérieure de la partie orientale de la petite chambre funéraire (des fragments d'amphores profilés et une croix trouvée dans cette même couche au-dessus de la grande chambre funéraire permettent de proposer une datation approximative au $\mathrm{V}^{\mathrm{e}}-\mathrm{VI}^{\mathrm{e}}$ siècle).

Outre la croix évoquée ci-dessus, de type grec (à branches égales et extrémités élargies), il faut mentionner, parmi les objets peu ordinaires prélevés dans le caveau funéraire $n^{\circ} 220$, la monture en cornaline d'un anneau avec gemme (intaille en forme de corne de bouc), découverte dans la terre de remplissage de la petite chambre funéraire et datant du $\mathrm{II}^{\mathrm{e}}$-III' siècle. 
Le caveau funéraire $n^{\circ} 225$ et les caveaux-cénotaphes $n^{\text {os }}$ 226-227

Pour une raison inconnue, le caveau funéraire $n^{\circ} 225$, le plus occidental des trois caveaux monumentaux disposés en groupe serré, n'avait pas été achevé et formait un seul et même ensemble funéraire et commémoratif avec les deux caveaux-cénotaphes $\left(n^{\text {os }} 226-227\right)$ et les vestiges de repas funéraires rituels accomplis tout près de là ${ }^{42}$.

Le caveau $\mathrm{n}^{\circ} 225$ présentait la même orientation vers le sud que les deux caveaux voisins ( $\mathrm{n}^{\text {os }} 213$ et 220 ) : le dromos menait depuis le sud dans la chambre funéraire, couverte dans l'Antiquité d'une voûte en berceau. Toutefois, au milieu du mur du fond (nord) de la chambre funéraire se trouvait encore une baie d'entrée couverte d'une arche qui conduisait non pas à la seconde chambre funéraire, mais aux caveauxcénotaphes ( $\left.\mathrm{n}^{\text {os }} 226-227\right)$ et à l'aire rituelle enclose devant eux (fig. 13).

Le dromos du caveau présentait un plan rectangulaire. Il avait été creusé dans le sol argileux en place et revêtu de pierres sur ses deux faces. Sa longueur atteignait 2,0-2,2 m, pour une largeur de 1,6-1,7 m (il allait en s'élargissant vers l'entrée de la chambre funéraire). Le mur côté est, d'une hauteur de 2,30-2,35 m, était formé de cinq assises de maçonnerie. Le mur côté ouest, d'une hauteur de $1,85 \mathrm{~m}$, comptait quatre assises. Tous les moellons étaient appareillés.

Dans la partie sud du dromos, le sol était formé par le terrain naturel aplani. Les marches ou la rampe menant à l'entrée ont peut-être été détruites lors de la réutilisation du caveau funéraire et de l'aménagement de l'escalier pénétrant dans le dromos. Dans la partie nord, devant le seuil, une dalle fendue de forme rectangulaire $(1,20 \times 1,05-1,15 \mathrm{~m})$ occupait presque toute la largeur; son épaisseur était d'au moins 8-10 cm.

Le dromos menait à la baie d'entrée, d'une largeur de $90 \mathrm{~cm}$. À l'est de la baie d'entrée, le mur qui séparait le dromos de la chambre funéraire était conservé sur une hauteur de 1,3-1,5 m.

La chambre du caveau $\mathrm{n}^{\circ} 225$ présentait un plan rectangulaire $(3,5$ x 4,6 m) et s'étendait dans le sens nord-sud. La hauteur maximale des murs (dont quatre à six assises étaient conservées) était de 2,4-2,5 m (!). À en juger par les moellons d'angle, la chambre était couverte d'une voûte en berceau.

42. V. A. Khršanovskij, «Èlitnyj sklep-kenotaf na Iluratskom plato». 
Fig. 13 - Nécropole sud-ouest de type mixte. Caveau-cénotaphe $\mathrm{n}^{\text {os }} 225-227$. Vue depuis le sud. Photographie de Larisa Assel'. Infographie de D. Glauser (C) UNIL/IASA. 
Au milieu du mur nord était aménagée une baie d'entrée (largeur env. $1 \mathrm{~m}$; profondeur $55 \mathrm{~cm}$ ). À une hauteur de $1,23 \mathrm{~m}$ depuis le niveau du seuil, de chaque côté, étaient conservés in situ les sommiers de l'arc qui couvrait autrefois la baie. La partie inférieure de la baie d'entrée avait été obstruée depuis l'extérieur (côté nord) par deux rangées de moellons grossièrement taillés. Ce bouchon de maçonnerie avait une hauteur de $70 \mathrm{~cm}$. Par la technique et la manière architecturale, il était en contraste manifeste avec le caveau funéraire.

Le sol de la chambre funéraire était revêtu de dalles de calcaire. Ce pavage était conservé sur presque toute la surface, à l'exception de quelques dalles manquant dans la partie ouest. Les dalles avaient pour l'essentiel une forme rectangulaire ou quasi rectangulaire, avec des dimensions allant de $0,40 \times 0,17 \mathrm{~m}$ à $1,15 \times 0,85 \mathrm{~m}$, mais il y avait aussi des dalles en forme de quadrilatère irrégulier. Leur épaisseur était de 8 à $10 \mathrm{~cm}$. Leur disposition ne paraissait pas suivre une ordonnance quelconque. Dans l'angle nord-est de la chambre funéraire, on a observé dans les dalles du pavage quatre cavités longitudinales (mesurant de $4 \mathrm{x}$ $13 \mathrm{~cm}$ à $6 \times 17 \mathrm{~cm}$ ), qui formaient en plan un rectangle presque régulier (1,8-1,9 x 0,4-0,5 m). La cohérence de leur disposition et les dimensions de l'espace qu'elles délimitaient amènent à supposer que, à l'instar des autres caveaux, elles étaient destinées à recevoir les pieds d'un support sur lequel était installé le cercueil.

En plus de ces cavités longitudinales, on a remarqué sur plusieurs dalles du pavage des lunules d'un diamètre de 3 à $10 \mathrm{~cm}$, pour une profondeur de 3 à $5 \mathrm{~cm}$. Il y en avait une vingtaine en tout. Elles se répartissaient essentiellement dans la partie sud de la chambre funéraire, sauf quelques-unes sur les dalles les plus au nord. Leur signification était probablement en rapport avec les actes rituels accomplis dans la chambre funéraire.

La terre remuée qui constituait le remplissage du caveau funéraire a fourni des restes osseux humains (au moins 22 individus adultes et 7 enfants), mais aussi d'animaux et d'oiseaux. La localisation du matériel ostéologique ne permet pas de le mettre en relation avec l'une ou l'autre des périodes d'utilisation du caveau et invite à penser qu'il constitue plutôt une phase ultérieure.

Les divers groupes d'objets découverts dans le dromos et la chambre funéraire du caveau no 225 peuvent être répartis en trois périodes: 
- fin du Ir et première moitié du II siècle (époque de la construction et de la première utilisation du caveau);

- II ${ }^{\mathrm{e}}$-III ${ }^{\mathrm{e}}$ siècle (utilisation secondaire pour des inhumations collectives);

- Antiquité tardive ou haut Moyen Âge, avec la construction d'un escalier à marches de pierre à travers le dromos pour atteindre la chambre funéraire.

Parmi les objets les plus anciens contemporains de la construction du caveau et de sa première utilisation (fin du $\mathrm{I}^{\text {er }}$ et première moitié du $\mathrm{II}^{\mathrm{e}}$ siècle) se trouvent des fragments d'amphores profilés, des poteries à vernis rouge, des lampes et des statuettes de terre cuite, dont le protomé d'un type rare d'une déesse portant une haute coiffure ${ }^{43}$.

Derrière le mur nord de la chambre funéraire du caveau $n^{\circ} 225$, où l'on se serait attendu à trouver une seconde chambre, est apparue une aire rituelle avec des restes de plusieurs repas funéraires, délimitée à l'est et à l'ouest par des murs faits de moellons de dimensions variables et de pierres non équarries, d'une hauteur de 1,7 et $3 \mathrm{~m}$ (!) respectivement. En plus de l'aire rituelle avec un mobilier dont la datation se situe à la limite entre le $\mathrm{I}^{\mathrm{er}}$ et le $\mathrm{II}^{\mathrm{e}}$ siècle, on a découvert, juste en face de la baie d'entrée, dans le mur nord, les deux caveaux-cénotaphes n ${ }^{\text {os }} 226$ et 227 .

Le caveau-cénotaphe $\mathrm{n}^{\circ} 226$ se trouvait à une distance d'environ $1 \mathrm{~m}$ du mur nord du caveau ${ }^{\circ} 225$, juste en face de la baie d'entrée aménagée dans le mur nord de la chambre funéraire. Son seuil était cependant à un niveau nettement plus élevé (de 1,4-1,5 m) que celui de la chambre, et atteignait presque celui des sommiers de l'arc de la baie. Le caveau, bâti en dalles de calcaire posées de chant, présentait un plan rectangulaire et une orientation vers le sud (avec une très légère déviation vers le nordouest/sud-est). Il mesurait 2,3-2,5 m de long, 1,0-1,2 $\mathrm{m}$ de large et 1,45$1,50 \mathrm{~m}$ de haut. La baie d'entrée, d'une largeur de 70-60 cm et d'une hauteur de $95 \mathrm{~cm}$, est obstruée par trois moellons équarris. Le sol de la chambre funéraire était constitué par la couche d'argile naturelle aplanie. L'ensemble de la construction était couvert de trois dalles de calcaire.

Le caveau-cénotaphe $n^{\circ} 227$ présentait, par rapport au no 226, une disposition en miroir, c'est-à-dire avec l'entrée au nord. En plan,

43. V. A. Khršanovskij, "Sklepy I - pervoj poloviny II vv. na Iluratskom plato", p. 396 ; Z. V. Khanutina, "Terrakotovaja protoma iz Ilurata» et "Terrakoty iz pogrebal'no-pominal'nykh kompleksov Iluratskogo plato", p. 223 sq. 
il formait également un rectangle régulier. Il était orienté vers le sud, avec une légère déviation vers le nord-ouest/sud-est. De même que le caveau voisin, il était bâti en dalles de calcaire posées de chant. Il mesurait 2,4-2,3 $\mathrm{m}$ de long, $75-80 \mathrm{~cm}$ de large et $1,35 \mathrm{~m}$ de haut. La baie d'entrée $(0,75 \times 1,45 \mathrm{~m})$ de la chambre funéraire était obstruée par une dalle de calcaire dressée verticalement, de forme rectangulaire avec un bord supérieur irrégulier, mesurant $80-97 \mathrm{~cm}$ de large, 1,95 $\mathrm{m}$ de haut et $8-12 \mathrm{~cm}$ d'épaisseur. Les caveaux $\mathrm{n}^{\text {os }} 226$ et 227 avaient un muret intérieur commun et une couverture commune faite de trois dalles de calcaire posées en travers.

Les objets trouvés dans les caveaux $n^{\text {os }} 226$ et 227 sont pratiquement identiques: on note dans chacun une série d'appliques de plâtre (avec quelques différences). Ces appliques sont en mauvais état de conservation. Parmi celles trouvées dans le caveau $\mathrm{n}^{\circ} 226$, on devine des représentations de Niobides, d'un jeune Niobide blessé, des masques de théâtre, des protomés de femme (?). Ces derniers types se rencontrent également dans le caveau $\mathrm{n}^{\circ} 227$. Ici cependant, on ne trouve pas de représentations de Niobides, mais une tête de félin (panthère?). On n'a par ailleurs découvert aucun indice ou reste de cercueils de bois que les appliques de plâtre servaient habituellement à décorer. Sur le sol de chacun des caveaux funéraires, on a trouvé des lampes, l'une en argile grise avec prolongement en bec, l'autre arrondie à vernis rouge ${ }^{44}$ et, dans la terre de remplissage de l'un et l'autre, un squelette de serpent.

Les trois plus grands caveaux funéraires du plateau d'Ilouraton (n ${ }^{\text {os }} 213,220$ et 225), situés à proximité immédiate les uns des autres, ont tous été construits à la fin du $\mathrm{I}^{\mathrm{er}}$ ou dans la première moitié du $\mathrm{II}^{\mathrm{e}} \mathrm{s}$. apr. J.-C. Le premier a vraisemblablement été l'ensemble funéraire et commémoratif du caveau $n^{\circ} 225$, avec le double caveau-cénotaphe $n^{\circ} 226$ 227, puisque c'est précisément de là que proviennent les fragments d'amphores et les formes de céramique à vernis rouge les plus anciens. Cet ensemble témoigne ainsi sans aucun doute d'événements historiques survenus à la fin du I ${ }^{\text {er }}$ ou dans la première moitié du $\mathrm{II}^{\mathrm{e}}$ siècle.

Au vu des dimensions des trois caveaux funéraires $n^{\text {os }} 213,220$ et 225 , qui appartiennent aux cinq plus grands hypogées (par la superficie de la

44. V. A. Khršanovskij, "Sklepy I - pervoj poloviny II vv. na Iluratskom plato», p. 399-403, fig. 17-19 et «Èlitnyj sklep-kenotaf na Iluratskom plato», p. 133-135. 
chambre funéraire) du Bosphore à l'époque romaine ${ }^{45}$, et de leur regroupement en un seul endroit, indice assez sûr des relations de parenté (dynastiques ?) qui liaient ceux à qui ils étaient destinés, il est légitime de remettre en question leur appartenance à la population de la proche ville fortifiée d'Ilouraton (sauf à en réexaminer complètement le statut) et d'émettre l'hypothèse que les défunts qui y furent enterrés étaient peut-être des représentants de l'aristocratie bosporane ou d'une élite de nomades.

\section{Les sanctuaires du plateau d'Ilouraton}

Presque tous les archéologues, à commencer par le découvreur du site, Paul Du Brux, ont remarqué et relevé sur le plateau d'Ilouraton de nombreux aménagements, la plupart de plan circulaire, de divers diamètres, et chacun a proposé son interprétation ${ }^{46}$. Du Brux voyait dans une partie d'entre eux les tours d'un mur d'enceinte extérieur de l'acropole. Mais, reprenant après lui la question, Gajdukevič tint pour douteuse cette interprétation. Il observa sur le plan de Du Brux qu'il y avait des tours non seulement à l'intérieur du territoire délimité par l'enceinte, mais aussi à l'extérieur. De plus, ces nombreux cercles, d'un diamètre allant de 2-3 m à $30 \mathrm{~m}$, reportés ou non sur le plan de Du Brux, «ne donnent pas l'impression de constructions monumentales propres à remplir une fonction de défense militaire» et ressemblent plutôt à des enclos sommaires aménagés avec des matériaux trouvés sur place ${ }^{47}$.

Gajdukevič émet alors l'idée d'une possible signification cultuelle (tertres à pierres dressées?), pour une partie au moins de ces aménagements. Il attire l'attention sur le fait que l'un de ces "cercles», dans le secteur sud du plateau, se trouve à proximité d'un hypogée découvert par Du Brux. Toutefois, après la fouille de deux de ces «cercles", faute d'y avoir trouvé un tombeau, il se tourne vers une autre interprétation.

La couche d'occupation découverte à l'intérieur des "cercles" étudiés (et contenant des dépôts de cendre, des ossements d'animaux, des tessons

45. V. A. Khršanovskij, "Sklepy I - pervoj poloviny II vv. na Iluratskom plato», p. 404.

46. P. Du Brux, Sobranie sočinenij, t. I, p. 309 sq.; t. 2, p. 219, fig. 510 sq.

47. V. F. Gajdukevič, «Bosporskij gorod Ilurat», p. 188. 
de céramique et un fragment de meule en pierre) date selon lui du III e $^{-}$ $\mathrm{IV}^{\mathrm{e}}$ siècle, voire d'une époque plus tardive encore. Par conséquent, ces aménagements ne sont plus en relation avec la ville antique d'Ilouraton. En conclusion, Gajdukevič émet l'hypothèse que les «cercles» seraient plutôt "les vestiges d'un important camp de nomades plus tardif" ${ }^{48}$, peut-être d'un enclos à bétail ou d'une bordure de yourte du haut Moyen Âge (VIII'-IX siècle) ${ }^{49}$.

Les interprétations que proposaient Du Brux et Gajdukevič étaient en grande partie déterminées par l'idée qu'ils se faisaient de ce qui se trouvait sur le plateau au-delà des murs de la ville. Le premier y voyait en effet un village entouré lui aussi d'un mur d'enceinte fortifié, et le second, un dépotoir urbain avec des cendres et des déchets et au-dessus duquel, après sa mise hors d'usage, seraient apparus les "cercles».

Le contexte archéologique prit un autre aspect lorsqu'en 1947, Kublanov découvrit le caveau $\mathrm{n}^{\circ} 1$, respectivement la nécropole " $\mathrm{du}$ haut». Gajdukevič nota justement que les «cercles» se trouvaient désormais sur le terrain de la nécropole ${ }^{50}$. Mais, considérant à juste titre qu'ils appartiennent à plusieurs périodes différentes, il ne les mit aucunement en relation entre eux.

En 1968, Kublanov fouilla l'intérieur d'un de ces «cercles» dans le secteur nord-est du plateau, mais, ayant découvert du mobilier de la fin de l'Antiquité et du haut Moyen Âge, il mit un terme à des fouilles qui n'entraient plus dans le cadre chronologique de ses recherches sur la nécropole d'Ilouraton. Plus tard, en 1970-1972, il en explora un autre, à l'extrémité opposée du plateau, dans le secteur sud-ouest. Ce «cercle» fut alors déjà jugé digne de l'appellation provisoire de «sanctuaire». Kublanov le date du III ${ }^{\mathrm{e}}-\mathrm{IV}^{\mathrm{e}}$ siècle ${ }^{51}$, ce qui coïncide avec la limite chronologique inférieure des "cercles» fouillés par Gajdukevič. Lors de son réaménagement et de sa réutilisation, on avait gravé sur le sol rocheux un signe en forme de croix orienté selon l'axe est-ouest (avec une légère déviation). Cette phase "chrétienne» de l'utilisation du "sanctuaire" peut être datée du $\mathrm{V}^{\mathrm{e}}-\mathrm{VI} \mathrm{I}^{\mathrm{e}}$ siècle. Le mobilier le plus tardif de cet

\footnotetext{
48. Ibid.

49. V. F. Gajdukevič, "Ilurat», p. 137 sq.

50. Ibid., p. 139.

5I. M. M. Kublanov, «Raskopki nekropolja Ilurata», p. 122, n. 17.
} 
Fig. 14 - Sanctuaire $n^{\circ} 67$ avec inhumation secondaire d'époque hunnique. Vue depuis le sud. Photographie de Larisa Assel'.

ensemble (comme des autres "cercles» fouillés par Gajdukevič) est en relation avec l'époque khazare.

Au cours des trente dernières années (de 1984 à 2013), dans le secteur oriental du plateau d'Ilouraton, huit constructions similaires par leur forme, leurs dimensions et leur fonction supposée ont encore été fouillées: six «cercles» ( ${ }^{\text {os }} 67,102,103,161,229$ et 230, avec un diamètre de 2,8 à $7 \mathrm{~m}$ et une fondation rocheuse au-dessus de laquelle s'élève, sur une hauteur atteignant $1 \mathrm{~m}$, une maçonnerie irrégulière faite d'assises d'une à deux couches de pierres plates) et deux aménagements de forme quasi rectangulaire ( ${ }^{\text {os }} 162$ et 228). Ils étaient tous dépourvus de couverture et après leur dernière utilisation, elles ont été recouvertes de pierres. Le mobilier recueilli permet de proposer une nouvelle hypothèse quant à leur fonction - celle d'aménagements rituels, de sanctuaires - et de préciser le cadre chronologique de leur utilisation ${ }^{52}$.

52. V. A. Khršanovskij, "Pozdneantičnye pogrebenija na nekropole Ilurata» et «Bašni, krugi, svjatilišča», p. 53-57; Z. V. Khanutina, V. A. Khršanovskij, «Ritual'nye sooruženija na nekropole Ilurata"; V. A. Khršanovskij, "Kruglye svjatilišča na Iluratskom plato». 
Lors des fouilles ont été découverts, dans la terre du remblai, des éléments d'autel, des fosses sacrificielles, des traces de foyer et de sacrifices d'animaux, des objets qui pouvaient servir pour des actes rituels (meules utilisées comme autels de sacrifice, lampes de terre cuite, labrys de fer). La nature de ces objets amène à supposer qu'ils étaient tous en rapport avec un type d'aménagement sacré qui ne se trouvait auparavant pas à cet endroit.

La chronologie des «sanctuaires» est rendue difficile par la pauvreté du mobilier éventuellement contemporain de ces aménagements et par la présence de mobilier d'autres époques, soit manifestement plus ancien ${ }^{53}$, soit plus récent. Dans trois cas, on a constaté des traces certaines d'une utilisation secondaire du "cercle». Un de ces cercles a été réaménagé deux ou trois fois, et pour la dernière fois (!) peut-être au VII - -VIII ${ }^{\text {e }}$ siècle ${ }^{54}$. Dans un autre cas $\left(n^{0} 67\right)$ a été découverte une tombe secondaire dans le remblai, que le mobilier (dont notamment une petite monnaie de bronze de l'empereur Arcadius, 395-408) permet de dater de la première moitié du V $\mathrm{V}^{\mathrm{e}}$ siècle ${ }^{55}$ (fig. 14). Dans un troisième, très proche du site de la ville (fouillé en 1984 par V. A. Gorončarovskij et sans numéro), ont été découverts, en plus d'objets antiques, des murets de clôture faits d'une maçonnerie médiévale à appareil en épi, destinée à une utilisation secondaire (!).

Le seul repère chronologique plus ou moins sûr que donne le mobilier archéologique est constitué par des fragments profilés d'amphores en argile rose, d'amphores en argile rouge à panse côtelée et d'amphores tardives en argile claire. Ces objets peuvent être datés largement entre la fin du III et le $\mathrm{V}^{\mathrm{e}}$ siècle. La plus grande partie de la céramique tournée (en argile rouge, à vernis rouge, en argile grise) peut être attribuée à la même période. Le corpus comprend aussi des tessons de céramique de l'époque khazare (céramique fabriquée au "tour lent", avec un décor de lignes et de surfaces, céramique modelée du type de Saltovo et céramique médiévale à glaçure), trouvés principalement dans les couches supérieures, mais ils ne sont pas prépondérants.

53. V. A. Khršanovskij, «Asinkhronye vešči v pogrebal'no-pominal'nykh kompleksakh", p. 435 sq.

54. M. M. Kublanov, «Raskopki nekropolja Ilurata», p. 122, n. 17.

55. V. A. Khršanovskij, "Pozdneantičnye pogrebenija na nekropole Ilurata", p. $20-27$. 
L'étude archéozoologique a identifié des restes osseux de chevaux, de vaches, de moutons, de chèvres, de cochons, de lièvres, d'oiseaux (oie ou canard) et de poissons.

Ainsi, selon toutes les données à disposition à ce jour, et compte tenu des recherches de Gajdukevič et de Kublanov, les «sanctuaires circulaires» du plateau d'Ilouraton n'apparurent pas avant la fin du III ${ }^{\mathrm{e}}$ siècle et furent utilisés dans leur fonction initiale jusqu'au début $\mathrm{du} \mathrm{V}^{\mathrm{e}}$ siècle. En plus de la chronologie, la topographie est également un argument en faveur de leur origine "post-ilouratienne", puisqu'ils se répartissent sur l'ensemble du plateau sans organisation apparente ni lien avec des lieux de concentration de structures funéraires et commémoratives plus anciennes.

$\mathrm{Au} \mathrm{IV}^{\mathrm{e}}$ siècle, le plateau d'Ilouraton, à une seule exception près, cessa donc d'être utilisé dans la fonction qu'il avait jusqu'alors, c'est-à-dire celle d'un lieu d'accomplissement de rites funéraires et commémoratifs, pour devenir un lieu de construction de sanctuaires d'un type complètement nouveau ${ }^{56}$.

La question de l'appartenance ethnoculturelle des sanctuaires du plateau d'Ilouraton reste pour l'instant sans réponse. Leur apparition au $\mathrm{IV}^{\mathrm{e}}$ siècle permet de supposer un rapport avec la nouvelle vague des Alano-Sarmates qui, après les incursions "gothiques", se mirent en mouvement depuis le Palus Méotide pour gagner la presqu'île de Kertch ${ }^{57}$. À peu près à cette même époque, les Alains s'établirent également dans d'autres colonies du Bosphore européen, ainsi par exemple à Belinskoe ${ }^{58}$. Toutefois, pour pouvoir tirer des conclusions concrètes et mieux étayées quant à l'appartenance ethnoculturelle des sanctuaires du plateau d'Ilouraton, il est indispensable de disposer d'un mobilier archéologique et d'un matériel anthropologique plus complet qui confirmeraient ou réfuteraient la thèse alano-sarmate.

La topographie et la chronologie inhabituelles des nécropoles et des sanctuaires du plateau d'Ilouraton, leur longue durée d'utilisation - du

56. V. A. Khršanovskij, «Kruglye svjatilišča na Iluratskom plato».

57. A. A. Maslennikov, Naselenie Bosporskogo gosudarstva v pervykh vekakh n. è., p. 40 ; S. F. Strželeckij, T. N. Vysotskaja, L. A. Ryžova, G. I. Žestkova, «Naselenie okrugi Khersonesa v pervoj polovine I tysjačeletija novoj èry", p. 193.

58. V. G. Zubarev, «K voprosu ob ètničeskom sostave žitelej sel'skikh poselenij Evropejskogo Bospora v III-IV vv. n. è.», p. 177 sq. 
$\mathrm{I}^{\mathrm{er}}$ au XIII siècle $^{59}$ - interdisent de les mettre en relation exclusivement avec la ville fortifiée antique d'Ilouraton, qui eut deux cents ans d'existence - du milieu du $\mathrm{I}^{\mathrm{er}}$ siècle aux années 260 - et donnent des raisons de supposer qu'aux yeux des hommes de l'Antiquité, ce plateau avait un statut "sacré» ${ }^{60}$ qui fit si longtemps son attrait.

Vladimir Andreevič KHRŠAnOvsKiJ Institut d'archéologie de l'Académie des sciences de Russie, Saint-Pétersbourg

Traduction du russe de Laurent Auberson

59. V. A. Khršanovskij, «Nekropol’ bez akropolja» et «Arkheologičeskie issledovanija Iluratskogo plato (retrospektiva i perspektiva)».

6o. V. A. Khršanovskij, «Sakral'naja topografija Iluratskogo plato». 


\section{BIBLIOGRAPHIE}

Du Brux, Paul, Euvres [Tome I. Textes; Tome II. Illustrations], SaintPétersbourg, Éditions Kolo, 2010.

Gajdukevič, Viktor Francevič, "Bosporskij gorod Ilurat» ["La cité bosporane d'Ilouraton»], Sovetskaja arkheologija, 13 (1950), p. 173-204.

—, "Ilurat. Itogi arkheologičeskikh issledovanij 1948-1953 gg." ["Ilouraton. Bilan des recherches archéologiques des années 1948 à 1953 », Materialy $i$ issledovanija po arkheologii, 85 (1958), p. 9-148.

Gorončarovskij, Vladimir Anatol'evič, "Terrakotovaja statuja ženskogo božestva iz raskopok nekropolja Ilurata: Afrodita ili Fortuna?» "Une statuette de terre cuite d'une divinité découverte dans les fouilles de la nécropole d'Ilouraton: Aphrodite ou Fortuna?», in $\Sigma Y \Sigma \Sigma I T I A$. Pamjati Jurija Viktoroviča Andreeva [Mélanges en mémoire de Jurij Viktorovič Andreev], SanktPeterburg, Aletejja, 2000, p. 255-257.

Gorončarovskij, Vladimir Anatol'evič, Khršanovskij, Vladimir Andreevič, "Raskopki verkhnego nekropolja Ilurata» [«Fouilles de la nécropole du haut à Ilouraton »], in Arkheologičeskie issledovanija v Krymu 1993 god [Recherches archéologiques en Crimée en 1993], Simferopol', Tavrija, 1994, p. 84-86.

Khanutina, Zoja Vladimirovna, "Terrakotovaja protoma iz Ilurata» ["Un protomé de terre cuite découvert à Ilouraton»], in Bospor i Severnoe Pričernomor'e v antičnuju èpokhu. Materialy meždunarodnogo jubilejnogo kruglogo stola, posvjaščjonnaja desjatiletiju konferencii "Bosporskij fenomen" [Le Bosphore et le littoral nord de la mer Noire à l'époque antique. Communications de la table ronde organisée à l'occasion des dix ans du congrès "Le phénomène bosporan»], Sankt-Peterburg, Nestor-Istorija, 2008, p. 139-141.

—, «Terrakoty iz pogrebal'no-pominal'nykh kompleksov Iluratskogo plato» [Les terres cuites provenant des ensembles funéraires et 
commémoratifs du plateau d'Ilouraton »], in Bosporskij fenomen. Naselenie, jazyki, kontakty. Materialy meždunarodnoj naučnoj konferencii [Le phénomène bosporan. Population, langues, contacts. Communications du congrès scientifique international], SanktPeterburg, Nestor-Istorija, 2011, p. 219-228.

Khanutina, Zoja Vladimirovna, Khršanovskij, Vladimir Andreevič, «Ritual'nye sooruženija na nekropole Ilurata» [«Des constructions à fonction rituelles dans la nécropole d'Ilouraton»], in Bosporskie issledovanija [Études bosporanes], III, otv. red. Viktor Nikolaevič Zin'ko Simferopol', Kerčenskaja Gorodskaja Tipografija, 2003, p. 315-328.

KhršAnovskiJ, Vladimir Andreevič, "Pozdneantičnye pogrebenija na nekropole Ilurata» [Sépultures de l'Antiquité tardive dans la nécropole d'Ilouraton"], in Naučno-ateističeskie issledovanija $v$ muzejakh [Recherches scientifiques et athées dans les musées], Leningrad, Izdatel'stvo Gosudarstvennogo Muzeja istorii religii i ateizma, 1988, p. 16-27.

—, "Bašni, krugi, svjatilišča » ["Tours, cercles, sanctuaires»], in Bosporskij fenomen. Grečeskaja kul'tura na periferii antičnogo mira. Materialy meždunarodnoj naučnoj konferencii [Le phénomène bosporan. La civilisation grecque à la périphérie du monde antique. Communications du congrès scientifique international], SanktPeterburg, Sintez-Poligraf, 1999, p. 52-57.

—, «Pogrebal'nyj kompleks rimskogo vremeni na nekropole Ilurata» ["Un ensemble funéraire d'époque romaine dans la nécropole d'Ilouraton "], in Bospor Kimmerijskij, Pont i varvarskij mir v èpokhu antičnosti i srednevekov' ja. Materialy III Bosporskikh čtenij [Le Bosphore Cimmérien, le Pont et le monde barbare dans l'Antiquité et au Moyen Âge. Contributions au III e cycle de conférences sur le Bosphore], Kertch, Kerčenskaja Gorodskaja Tipografija, 2002, p. 255-258.

—, «Novyj sklep s polucirkul'nym svodom na nekropole Ilurata» [«Un nouveau caveau funéraire à voûte en berceau dans la nécropole d'Ilouraton »], Arkheologija, 3 (2003), p. 21-31.

—, «Nekropol' bez akropolja (nekropol' Ilurata v IV-XIII vv. n. è.)» ["Une nécropole sans acropole (la nécropole d'Ilouraton du IV au XIII siècle»], in Bospor Kimmerijskij i varvarskij mir v period antičnosti i srednevekov'ja. Periody destabilizacij i katastrof. 
Materialy VI Bosporskikh čtenij [Le Bosphore Cimmérien et le monde barbare dans l'Antiquité et au Moyen Âge. Périodes de déstabilisation et de bouleversements. Contributions au VIe cycle de conférences sur le Bosphore], Kertch, Kerčenskaja Gorodskaja Tipografija, 2005, p. 343-347.

—, "Gruntovye žertvennye jamy na nekropole Ilurata» ["Des fosses sacrificielles dans la nécropole d'Ilouraton"], in Bospor Kimmerijskij i varvarskij mir v period antičnosti i srednevekov' ja. Svjatilišča i sakral'nye ob"ekty. Materialy VIII Bosporskikh čtenij [Le Bosphore Cimmérien et le monde barbare dans l'Antiquité et au Moyen Âge. Sanctuaires et objets sacrés. Contributions au VIII cycle de conférences sur le Bosphore], Kertch, Kerčenskaja Gorodskaja Tipografija, 2007, p. 318-328.

—, «Pogrebal'no-pominal'nye kompleksy vtoroj poloviny I - pervoj poloviny II vv. n. è. na nekropole Ilurata» ["Des ensembles funéraires et commémoratifs de la deuxième moitié du I ${ }^{\text {er }}$ à la première moitié du II siècle dans la nécropole d'Ilouraton »], in Drevnosti Bospora [Antiquités du Bosphore], t. 14, Moskva, Triumf print, 2010, p. 583-609.

—, «Sklepy I - pervoj poloviny II vv. na Iluratskom plato» [ "Des caveaux funéraires du $\mathrm{I}^{\mathrm{er}}$ siècle et de la première moitié du $\mathrm{II}^{\mathrm{e}}$ siècle sur le plateau d'Ilouraton »], in Drevnosti Bospora [Antiquités du Bosphore], t. 15, Moskva, Triumf print, 2011, p. 371-410.

—, «Sklepy-katakomby na Iluratskom plato : tipologija, khronologija, problemy ètnokul'turnoj prinadležnosti» " Les caveaux-hypogées du plateau d'Ilouraton: typologie, chronologie, problèmes d'appartenance ethnoculturelle»], in Drevnosti Bospora [Antiquités du Bosphore], t. 16, Moskva, Triumf print, 2012, p. 526-547.

—, «Sakral'naja topografija Iluratskogo plato» [«La topographie sacrée du plateau d'Ilouraton "], in Bosporskij fenomen. Greki i varvary na evrazijskom perekrjostke. Materialy meždunarodnoj naučnoj konferencii [Le phénomène bosporan. Grecs et barbares au carrefour eurasiatique. Communications du congrès scientifique international], Sankt-Peterburg, Nestor-Istorija, 2013, p. 248-255.

—, «Asinkhronye vešči v pogrebal'no-pominal'nykh kompleksakh (po materialam nekropolej Kiteja i Iluratskogo plato)» ["Objets non synchrones dans des ensembles funéraires et commémoratifs (d'après les nécropoles de Kytée et du plateau d'Ilouraton)»], in 
Bospor Kimmerijskij $i$ varvarskij mir v period antičnosti i srednevekov'ja. Aktual'nye problemy. Materialy XV Bosporskikh čtenij [Le Bosphore Cimmérien et le monde barbare dans l'Antiquité et au Moyen Âge. Problèmes actuels. Contributions au XVe cycle de conférences sur le Bosphore], Kertch, Kerčenskaja Gorodskaja Tipografija, 2014, p. 433-438.

—, "Arkheologičeskie issledovanija Iluratskogo plato (retrospektiva i perspektiva)» "LLes recherches archéologique sur le plateau d'Ilouraton (rétrospective et perspectives)»], in Pogrebal'naja kul'tura Bosporskogo carstva. Materialy kruglogo stola, posvjaščjonnogo stoletiju so dnja roždenija M. M. Kublanova [La culture funéraire du royaume du Bosphore. Communications de la table ronde organisée à l'occasion du centième anniversaire de la naissance de M. M. Kublanov], Sankt-Peterburg, Nestor-Istorija, 2014, p. 172-182.

—, «Kruglye svjatilišča na Iluratskom plato. Problemy khronologii i ètnokul'turnoj prinadležnosti » " Les sanctuaires circulaires sur le plateau d'Ilouraton. Problèmes de chronologie et d'appartenance ethnoculturelle»], Tavričeskie studii. Istoričeskie nauki, 7 (2015), p. 142-147.

—, «Ëlitnyj sklep-kenotaf na Iluratskom plato» [ Un caveau funéraire aristocratique à cénotaphe sur le plateau d'Ilouraton»], in Ėlita Bospora i bosporskaja èlitarnaja kul'tura. Materialy meždunarodnogo kruglogo stola [Élites du Bosphore et culture aristocratique bosporane. Communications de la table ronde internationale], Sankt-Peterburg, Palazzo, 2016, p. 130-136.

Kublanov, Mikhail Moiseevič, "Itogi arkheologičeskikh izyskanij v rajone der. Ivanovka (Kerčenskij poluostrov) v 1947 godu» ["Résultats des recherches archéologiques dans le district du village d'Ivanovka (presqu'île de Kertch) »], in Učjonye zapiski LGPI im. A. I. Gercena [Notes savantes du LGPI du nom de A. I. Herzen], t. 68, Leningrad, 1948, p. 27-53.

—, «Raskopki nekropolja Ilurata v 1969 g.» [ "Fouilles de la nécropole d'Ilouraton en 1969 »], in Kratkie soobšćenija Instituta arkheologii [Communications de l'Institut d'archéologie], no 130, Moskva, Nauka, 1972, p. 83-88.

—, "Novye pamjatniki nekropolja Ilurata» ["Nouveaux monuments de la nécropole d'Ilouraton»], in Kratkie soobščenija Instituta 
arkheologii [Communications de l'Institut d'archéologie], $\mathrm{n}^{\circ} 145$, Moskva, Nauka, 1976, p. 102-108.

—, "Novye pogrebal'nye sooruženija Ilurata» ["Nouvelles constructions funéraires à Ilouraton»], in Kratkie soobščenija Instituta arkheologii [Communications de l'Institut d'archéologie], no 159, Moskva, Nauka, 1979, p. 90-97.

—, «Raskopki nekropolja Ilurata. Itogi i problemy» [«Fouilles de la nécropole d'Ilouraton. Bilan et problèmes»], in Naučnoateističeskie issledovanija $v$ muzejakh [Recherches scientifiques et athées dans les musées], Leningrad, Izdatel'stvo Gosudarstvennogo Muzeja istorii religii i ateizma, 1983, p. 96-129.

Kublanov, Mikhail Moiseevič, KryžICKIJ, Sergej Dmitrievič, «Sklep $\mathrm{n}^{\circ} 18$ nekropolja Ilurata" [ "Le caveau funéraire $\mathrm{n}^{\circ} 18$ de la nécropole d'Ilouraton »], Arkheologija, 7 (1972), p. 45-46.

Kublanov, Mikhail Moiseevič, Khršanovskij, Vladimir Andreevič, "Nekropol' Ilurata: raskopki 1984-1988 godov" [ La nécropole d'Ilouraton: fouilles des années 1984-1988»], in Problemy religievedenija i ateizma $v$ muzejakh, Leningrad, Izdatel'stvo Gosudarstvennogo Muzeja istorii religii i ateizma, 1989, p. 6-42.

Maslennikov, Aleksandr Aleksandrovič, Naselenie Bosporskogo gosudarstva v pervykh vekakh $n$. è. [La population du royaume du Bosphore dans les premiers siècles de notre ère], Moskva, Nauka, 1990.

Moleva, Natal'ja Vladimirovna, Tul'pe, Irina Aleksandrovna, KhrŠAnOvsKiJ, Vladimir Andreevič, "Kostjanaja podelka iz Ilurata - bosporskij kalendar'?» [Un petit objet en os découvert à Ilouraton: un calendrier bosporan?»], in Bosporskij fenomen. Problemy khronologii i datirovki pamjatnikov. Materialy meždunarodnoj naučnoj konferencii [Le phénomène bosporan. Problèmes de chronologie et de datation des monuments. Communications du congrès scientifique international], otv. red. V. Yu. Zuev, Sankt-Peterburg, Izdatel'stvo Gosudarstvennogo Èrmitaža, 2004, p. 171-183.

Mordvinceva, Valentina Ivanovna, Trejster, Mikhail Jurevič, Proizvedenija torevtiki $i$ juvelirnogo iskusstva $v$ Severnom Pričernomor'e $2 v$. do n. è-2 v.n. è. [CEuvres de toreutique et de joaillerie du littoral nord de la mer Noire du II siècle av. au II e siècle apr. J.-C.], t. 1-3, Simferopol'/Bonn, Tarpan, 2007. 
Strželeckij, Stanislav Francevič, Vysotskaja, Tat'jana Nikolaevna, Ryžova, Ljudmila Aleksandrovna, Žestrova, Galina Ivanovna, «Naselenie okrugi Khersonesa v pervoj polovine I tysjačeletija novoj èry (po materialam nekropolja 'Sovkhoz $\mathrm{n}^{\circ} 10$ ')» [« La population des environs de Chersonèse durant la première moitié du premier millénaire de notre ère (d'après les matériaux de la nécropole 'Sovkhoz no 10')»], in Stratum plus 2003-2004, 4, Sankt-Peterburg, Chișinău, Odessa, București, Izdatel'stvo Vysšaja antropologičeskaja škola, 2005, p. 27-277.

Tunkina, Irina Vladimirovna, Russkaja nauka o klassičeskikh drevnostjakh juga Rossii (XVIII - seredina XIX vv.) [La recherche scientifique russe sur les antiquités classiques de la Russie méridionale (XVIII ${ }^{e}$ première moitié du XIX'e siècle)], Sankt-Peterburg, Nauka, 2002.

Zakharenkov, Nikolaj Vital'evič, "Gruntovyj sklep I v. n. è. na nekropole Ilurata» [ «Un caveau funéraire creusé en terre du I ${ }^{\text {er }}$ siècle de notre ère dans la nécropole d'Ilouraton "], in Bosporskij fenomen. Grečeskaja kul'tura na periferii antičnogo mira. Materialy meždunarodnoj naučnoj konferencii [Le phénomène bosporan. La civilisation grecque à la périphérie du monde antique. Communications $d u$ congrès scientifique international], SanktPeterburg, Sintez-Poligraf, 1999, p. 315-319.

Zakharenkov, Nikolaj Vital'evič, Khršanovskij, Vladimir Andreevič, Trejster, Mikhail Jurevič, «Vydajuščijsja pamjatnik pogrebal'noj arkhitektury nekropolja Ilurata» [ Un monument remarquable d'architecture funéraire de la nécropole d'Ilouraton »], in Istorik. Arkheolog. Literator. K 90-letiju M. M. Kublanova [Historien. Archéologue. Homme de lettres. À l'occasion du $90^{e}$ anniversaire de M. M. Kublanov], Sankt-Peterburg, Akcioner i K, 2004, p. 73-85.

Zubarev, Viktor Gennad'evič, Severnoe Pričernomor'e v istorikogeografičeskoj koncepcii Klavdija Ptolemeja [Le littoral nord de la mer Noire selon la conception historico-géographique de Claude Ptolémée], Tula, Izdatel'stvo Tul'skogo Gosudarstvennogo Pedagogičeskogo Universiteta im. L. N. Tolstogo, 1998.

—, «K voprosu ob ètničeskom sostave žitelej sel'skikh poselenij Evropejskogo Bospora v III-IV vv. n. è.» ["À propos de la composition ethnique de la population des villages du Bosphore européen aux III ${ }^{\mathrm{e}}-\mathrm{IV}^{\mathrm{e}}$ siècles»], in Bospor Kimmerijskij $i$ varvarskij mir v period antičnosti i srednevekov'ja. Aktual'nye problemy. 
Materialy X Bosporskikh čtenij [Le Bosphore Cimmérien et le monde barbare dans l'Antiquité et au Moyen Âge. Problèmes actuels. Contributions au $X^{e}$ cycle de conférences sur le Bosphore], Kertch, Kerčenskaja Gorodskaja Tipografija, 2009, p. 175-181. 